\title{
Identification of New Markers of Alcohol-Derived DNA Damage in Humans
}

\author{
Valeria Guidolin ${ }^{1,2}$, Erik S. Carlson ${ }^{2}{ }^{\mathbb{D}}$, Andrea Carrà ${ }^{2}$, Peter W. Villalta ${ }^{2}{ }^{(0)}$, Laura A. Maertens ${ }^{2}$, \\ Stephen S. Hecht ${ }^{2}$ and Silvia Balbo ${ }^{1,2, *}$ \\ 1 Division of Environmental Health Sciences, University of Minnesota, Minneapolis, MN 55455, USA; \\ guido019@umn.edu \\ 2 Masonic Cancer Center, University of Minnesota, 2231 6th Street SE, Minneapolis, MN 55455, USA; \\ erik_carlson@fas.harvard.edu (E.S.C.); andrea.carra.101184@gmail.com (A.C.); villa001@umn.edu (P.W.V.); \\ maert006@umn.edu (L.A.M.); hecht002@umn.edu (S.S.H.) \\ * Correspondence: balbo006@umn.edu
}

check for updates

Citation: Guidolin, V.; Carlson, E.S.; Carrà, A.; Villalta, P.W.; Maertens,

L.A.; Hecht, S.S.; Balbo, S.

Identification of New Markers of Alcohol-Derived DNA Damage in Humans. Biomolecules 2021, 11, 366. https: / / doi.org/10.3390/

biom 11030366

Academic Editor: Vladimir N. Uversky

Received: 15 January 2021

Accepted: 21 February 2021

Published: 27 February 2021

Publisher's Note: MDPI stays neutral with regard to jurisdictional claims in published maps and institutional affiliations.

Copyright: (C) 2021 by the authors. Licensee MDPI, Basel, Switzerland. This article is an open access article distributed under the terms and conditions of the Creative Commons Attribution (CC BY) license (https:// creativecommons.org/licenses/by/ $4.0 /)$.

\begin{abstract}
Alcohol consumption is a risk factor for the development of several cancers, including those of the head and neck and the esophagus. The underlying mechanisms of alcohol-induced carcinogenesis remain unclear; however, at these sites, alcohol-derived acetaldehyde seems to play a major role. By reacting with DNA, acetaldehyde generates covalent modifications (adducts) that can lead to mutations. Previous studies have shown a dose dependence between levels of a major acetaldehyde-derived DNA adduct and alcohol exposure in oral-cell DNA. The goal of this study was to optimize a mass spectrometry (MS)-based DNA adductomic approach to screen for all acetaldehyde-derived DNA adducts to more comprehensively characterize the genotoxic effects of acetaldehyde in humans. A high-resolution/-accurate-mass data-dependent constant-neutralloss-MS ${ }^{3}$ methodology was developed to profile acetaldehyde-DNA adducts in purified DNA. This resulted in the identification of 22 DNA adducts. In addition to the expected $N^{2}$-ethyldeoxyguanosine (after $\mathrm{NaBH}_{3} \mathrm{CN}$ reduction), two previously unreported adducts showed prominent signals in the mass spectra. $\mathrm{MS}^{\mathrm{n}}$ fragmentation spectra and accurate mass were used to hypothesize the structure of the two new adducts, which were then identified as $N^{6}$-ethyldeoxyadenosine and $N^{4}$ ethyldeoxycytidine by comparison with synthesized standards. These adducts were quantified in DNA isolated from oral cells collected from volunteers exposed to alcohol, revealing a significant increase after the exposure. In addition, 17 of the adducts identified in vitro were detected in these samples confirming our ability to more comprehensively characterize the DNA damage deriving from alcohol exposures.
\end{abstract}

Keywords: acetaldehyde; DNA adducts; adductomics; mass spectrometry; alcohol

\section{Introduction}

Globally, annual alcohol consumption has been estimated to be $6.4 \mathrm{~L}$ per capita in 2016 , and it is projected to increase to $7 \mathrm{~L}$ by 2025 [1]. Alcohol is classified by the International Agency for Research on Cancer (IARC) as a Group 1 human carcinogen and is estimated to be responsible for $12.6 \%$ of overall cancers [2,3], a percentage expected to increase following the growth in consumption. Alcohol is mainly metabolized in the body by alcohol dehydrogenases (ADHs), which oxidize ethanol to acetaldehyde, followed by detoxification to acetate by aldehyde dehydrogenases (ALDHs) [4]. The variant allele ALDH2*2 encodes for an inactive subunit of the enzyme ALDH2 [4]. Individuals who are heterozygous carriers of this variant, ALDH2* $1 /{ }^{*} 2$, have about $10 \%$ residual ALDH2 activity and experience side effects like flushing and nausea when ingesting alcohol [4]. These individuals inefficiently detoxify acetaldehyde and are at higher risk for developing alcohol-related esophageal and head and neck cancers $[4,5]$. These observations contributed to the reclassification of acetaldehyde associated with alcohol consumption as a Group 1 
human carcinogen by IARC [3]. Acetaldehyde reacts with DNA bases to produce adducts, which are critical in the carcinogenic process because they can cause miscoding resulting in mutated genes and loss of normal cellular growth-control mechanisms [4]. Although ethanol is mainly metabolized in the liver, the concentration of acetaldehyde in saliva after ingesting ethanol is much higher than in the blood, due to the local metabolism in the oral mucosa and the microflora. Therefore, acetaldehyde genotoxicity may play a specific key role in ethanol-induced carcinogenesis in the oral cavity [4].

The major adduct formed upon reaction of acetaldehyde with DNA is $N^{2}$-ethylidenede oxyguanosine ( $N^{2}$-ethylidene-dG), which can be analyzed as its more stable reduced version $N^{2}$-ethyldeoxyguanosine ( $N^{2}$-ethyl-dG) after DNA treatment with $\mathrm{NaBH}_{3} \mathrm{CN}$ [4]. Levels of this adduct showed a positive dose-response relationship in oral-cell DNA collected from volunteers who consumed increasing amounts of alcohol [6]. However, several other adducts as well as DNA-DNA crosslinks have been identified in the reactions of acetaldehyde with DNA and, together with modifications at other nucleobases, may also play a role in acetaldehyde's chemically induced carcinogenesis and epigenetic signaling [7-9]. To better understand the role of these other lesions, this study optimized and implemented our ultrasensitive data-dependent acquisition constant-neutral-loss triggered-MS ${ }^{3}$ (DDA$\mathrm{CNL} / \mathrm{MS}^{3}$ ) DNA adductomic method to screen for all acetaldehyde-derived DNA adducts and comprehensively characterize acetaldehyde-derived DNA damage. This approach allowed us to profile acetaldehyde-derived DNA modifications and successfully identify and screen for new markers of alcohol exposure and genotoxicity in humans.

\section{Materials and Methods}

Caution: acetaldehyde may cause cancer. It should be handled in a well-ventilated hood with extreme care and with personal protective equipment.

\subsection{Materials and Chemicals}

Acetaldehyde and [ethyl- $\mathrm{D}_{5}$ ] $\mathrm{EtNH}_{3} \mathrm{Cl}$ were purchased from Millipore Sigma (St. Louis, MO, USA). In addition, 6-Chloropurine-2'-deoxyriboside was obtained from Carbosynth (Compton, UK). Water (LC-MS grade), methanol (MeOH, LC-MS grade), acetonitrile (ACN, LC-MS grade), 2-propanol (IPA, LC-MS grade), and formic acid (FA, 98\% v/v) were purchased from Fisher Scientific (Hanover Park, IL, USA). Distilled water was purified by a Milli-Q system (Milford, MA, USA). Deoxyribonuclease I recombinant expressed by Pichia pastoris (R-DNase, 10,000 U/mg, phosphodiesterase-1 extracted from Crotalus adamanteus (PDE-1, $0.4 \mathrm{U} / \mathrm{mg}$, recombinant alkaline phosphatase expressed by Pichia pastoris (R-ALP, $7000 \mathrm{U} / \mathrm{mg}$, calf thymus DNA (CT-DNA, $5 \mathrm{mg}$ ), $\mathrm{NaBH}_{3} \mathrm{CN}$, acetaldehyde, Tris base, double-filtration membrane Amicon Ultra ( $30 \mathrm{kDa}$ cutoff, $0.5 \mathrm{~mL}$ ), and single-filtration membrane Microcone (10 kDa cutoff, $0.5 \mathrm{~mL}$ ) were purchased from Millipore Sigma (St. Louis, MO, USA). Silanized vials $(0.3 \mathrm{~mL}, 1.2 \mathrm{~mL}, 4 \mathrm{~mL}, 20 \mathrm{~mL}$ ) were purchased from ChromTech (Apple Valley, MN, USA). Cell lysis solution, protein precipitation solution, RNase A, and proteinase K were obtained from Qiagen (Hilden, Germany).

\subsection{General Synthetic Procedures}

NMR spectra were recorded on a Bruker $500 \mathrm{MHz}$ spectrometer. Chemical shifts are reported as parts per million (ppm). Residual solvent peaks were used as an internal

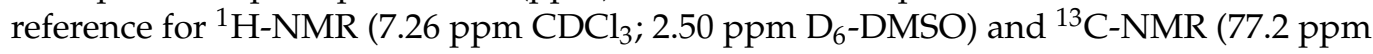
$\mathrm{CDCl}_{3} ; 39.5 \mathrm{ppm} \mathrm{D}_{6}$-DMSO). Peak splitting used the following abbreviations: $\mathrm{s}=$ singlet, $\mathrm{d}=$ doublet, $\mathrm{t}=$ triplet, $\mathrm{q}=$ quartet, $\mathrm{dd}=$ doublet of doublets, $\mathrm{dt}=$ doublet of triplets, $\mathrm{ddd}=$ doublet of doublet of doublets, $\mathrm{bs}=$ broad singlet, and $\mathrm{m}=$ multiplet. All compound structures were evaluated and confirmed with ${ }^{1} \mathrm{H},{ }^{13} \mathrm{C}$, COSY, HSQC, and HMBC experiments. High-resolution mass spectrometry (HRMS) for selected compounds was performed on an Orbitrap Fusion Tribrid mass spectrometer (Thermo Scientific, Waltham, MA, USA) and reported as $m / z$. Thin-layer chromatography (TLC) utilized Polygram precoated silica gel TLC plates $(40 \times 80 \mathrm{~mm}, 0.2 \mathrm{~mm}$ thick) with $254 \mathrm{~nm}$ fluorescent indicator. TLC 
plates were visualized by UV lamp irradiation. Flash chromatography was performed on SiliCycle 60 (70-150) mesh silica gel. Reactions were performed with oven-dried glassware and under an atmosphere of $\mathrm{N}_{2}$, unless specified otherwise.

\subsection{Synthesis of $3^{\prime}, 5^{\prime}$-bis-O-acetyl-2'-deoxyuridine}

To a $25 \mathrm{~mL}$, round-bottom flask equipped with a magnetic stir bar, were added $2^{\prime}$ deoxyuridine (154.9 mg, $0.679 \mathrm{mmol})$, 4-dimethylaminopyridine (5.6 mg, $0.0458 \mathrm{mmol}$ ), triethylamine $(275.9 \mathrm{mg}, 2.73 \mathrm{mmol}, 380 \mu \mathrm{L})$, and ACN $(3.5 \mathrm{~mL})$. The resulting suspension was treated with acetic anhydride $(280.8 \mathrm{mg}, 2.75 \mathrm{mmol}, 260 \mu \mathrm{L})$ and stirred at room temperature for $30 \mathrm{~min}$. The reaction was quenched with $\mathrm{MeOH}(1 \mathrm{~mL})$ and evaporated in vacuo. The resulting oil was reconstituted in $\mathrm{CH}_{2} \mathrm{Cl}_{2}$ and washed once with brine. The organic layer was dried over $\mathrm{MgSO}_{4}$, filtered, and evaporated to a crude foam. Purification by flash column chromatography (1:3:1 hexanes/EtOAc/ $\mathrm{CH}_{2} \mathrm{Cl}_{2}$ ) provided pure product as a white foam $(183.3 \mathrm{mg}, 86.5 \%)$.

\subsection{Synthesis of 4-chloro-1-N-(3', 5'-bis-O-acetyl-2'-deoxyribosyl)-2-pyrimidinone}

To an oven-dried, two-neck, $25 \mathrm{~mL}$ flask equipped with a magnetic stir bar were added $3^{\prime}, 5^{\prime}$-bis-O-acetyl-2'-deoxyuridine $(293.3 \mathrm{mg}, 0.94 \mathrm{mmol})$ and anhydrous $\mathrm{CHCl}_{3}(10 \mathrm{~mL})$. The flask was purged with argon thrice and then $\mathrm{SOCl}_{2}(85.3 \mathrm{mg}, 7.17 \mathrm{mmol}, 520 \mu \mathrm{L})$ and DMF $(50 \mu \mathrm{L})$ were added. The resulting yellow solution was brought to reflux $\left(\sim 75^{\circ} \mathrm{C}\right)$ for $2 \mathrm{~h}$. After this time, the reaction mixture was cooled to room temperature and quenched with $\mathrm{NaHCO}_{3}(\sim 5 \mathrm{~mL})$. Once bubbling ceased, the organic layer was collected, and the remaining aqueous layer was extracted once with $\mathrm{CH}_{2} \mathrm{Cl}_{2}(10 \mathrm{~mL})$. The pooled organics were dried over $\mathrm{MgSO}_{4}$, filtered, and evaporated in vacuo to a yellow oil. Purification by column chromatography $\left(1 \% \rightarrow 2 \% \mathrm{MeOH}\right.$ in $\left.\mathrm{CHCl}_{3}\right)$ delivered pure product as an off-white solid (186.5 mg, 60\%).

\subsection{Synthesis of $N^{4}$-ethyldeoxycytidine}

4-Chloro-1-N-(3', 5'-bis-O-acetyl-2'-deoxyribosyl)-2-pyrimidinone (7.4 mg, $0.0224 \mathrm{mmol}$ ), $\mathrm{K}_{2} \mathrm{CO}_{3}(30.8 \mathrm{mg}, 0.223 \mathrm{mmol})$, and $\mathrm{ACN}(1 \mathrm{~mL})$ were combined in a two-dram vial equipped with a magnetic stir bar. The cloudy suspension was treated with $\mathrm{EtNH}_{3} \mathrm{Cl}(10.1 \mathrm{mg}$, $0.124 \mathrm{mmol}$ ) and heated to $50^{\circ} \mathrm{C}$ for $2 \mathrm{~h}$. After cooling to room temperature, the solvent was removed in vacuo. The residue was then reconstituted in $\mathrm{MeOH}(1 \mathrm{~mL})$ and stirred at $50{ }^{\circ} \mathrm{C}$ for an additional $2 \mathrm{~h}$. The mixture was similarly cooled to room temperature and concentrated to dryness in vacuo. The resulting solid was reconstituted in $\mathrm{H}_{2} \mathrm{O}(3 \mathrm{~mL})$ and purified by HPLC (Agilent 1100 Analytical Flow, Agilent Technologies, Palo Alto, CA, USA). Separation was performed using a Luna C18 column $(250 \times 4.6 \mathrm{~mm}, 100 \mathrm{~A}$, $40{ }^{\circ} \mathrm{C}$ ) with a multistep gradient at a flow rate of $1 \mathrm{~mL} / \mathrm{min}$ using $\mathrm{H}_{2} \mathrm{O}$ and $\mathrm{MeOH}$ as solvents A and B, respectively. Beginning at $2 \%$ B, the eluent was brought to $27 \%$ B over $15 \mathrm{~min}$. This was followed by a wash at $95 \%$ B for $2 \mathrm{~min}$ and re-equilibration. Detection was accomplished using UV-Vis $(254 \mathrm{~nm})$. The product eluted at $16.2 \mathrm{~min}$ and was collected in a glass vial. After evaporation in vacuo, pure product was isolated as a white solid (3.72 mg, 65.1\%).

\subsection{Synthesis of $\left[D_{5}\right] N^{4}-$ ethyldeoxycytidine}

This compound was produced analogously to $N^{4}$-ethyldeoxycytidine ( $N^{4}$-ethyl-dC), except that [ethyl- $\mathrm{D}_{5}$ ] $\mathrm{EtNH}_{3} \mathrm{Cl}$ was used. The product was isolated as a white solid (5.61 $\mathrm{mg}, 64.2 \%)$.

\subsection{Synthesis of $N^{6}$-ethyldeoxyadenosine}

6-Chloropurine-2'-deoxyribose ( $11.3 \mathrm{mg}, 0.0417 \mathrm{mmol}), \mathrm{EtNH}_{3} \mathrm{Cl}(5.1 \mathrm{mg}, 0.0626 \mathrm{mmol})$, $\operatorname{iPr}_{2} \mathrm{EtN}(13.3 \mathrm{mg}, 0.103 \mathrm{mmol}, 18 \mu \mathrm{L})$ and DMSO $(1 \mathrm{~mL})$ were combined in a two-dram vial equipped with a magnetic stir bar. The solution was heated to $50{ }^{\circ} \mathrm{C}$ and stirred for $16 \mathrm{~h}$. The solution was then cooled to room temperature and diluted with $\mathrm{H}_{2} \mathrm{O}(1 \mathrm{~mL})$. The 
product was purified by HPLC (Agilent 1100 Analytical Flow, Agilent Technologies, Palo Alto, CA, USA). Separation was performed using a Luna C18 column $(250 \times 4.6 \mathrm{~mm}, 5 \mathrm{~A}$, $25^{\circ} \mathrm{C}$ ) with a multistep gradient at a flow rate of $1.5 \mathrm{~mL} / \mathrm{min}$ using $\mathrm{H}_{2} \mathrm{O}$ and $\mathrm{MeOH}$ as solvents A and B, respectively. The eluent was held at $2 \% \mathrm{~B}$ for $10 \mathrm{~min}$ and then brought to $50 \%$ B over $25 \mathrm{~min}$. This was followed by a wash at $95 \%$ B for $4 \mathrm{~min}$ and re-equilibration. Detection was accomplished using UV-Vis at $254 \mathrm{~nm}$. The product eluted at $22.4 \mathrm{~min}$ and was collected in a glass vial. After evaporation in vacuo, pure product was isolated as a white solid (3.60 mg, 30.5\%).

\subsection{Synthesis of $\left[D_{5}\right] N^{6}-e$ thyldeoxyadenosine}

This compound was produced analogously to $N^{6}$-ethyldeoxyadenosine ( $N^{6}$-ethyl$\mathrm{dA}$ ), except that [ethyl- $\mathrm{D}_{5}$ ] $\mathrm{EtNH}_{3} \mathrm{Cl}$ was used. The product was isolated as a white solid (3.29 $\mathrm{mg}, 27.8 \%$ ).

\subsection{DNA Incubation with Acetaldehyde and Stabilization}

The reaction of acetaldehyde with exocyclic amino groups of the DNA nucleobases forms unstable Schiff bases, which may be degraded during DNA hydrolysis [10,11]. To prevent degradation, the DNA was treated with the reducing agent $\mathrm{NaBH}_{3} \mathrm{CN}$ following a previously reported procedure [12]. Similarly, DNA hydrolysis was carried out as previously reported [12]. In brief, CT-DNA (1 mg) was incubated with acetaldehyde ( $5 \mathrm{mmol}$ ) in Tris-10 Mm HCl/5 mM MgCl 2 buffer ( $\mathrm{pH} \sim 7$ ) at $37^{\circ} \mathrm{C}$ for $24 \mathrm{~h}$. Subsequently, $30 \mathrm{mg} \mathrm{NaBH}{ }_{3} \mathrm{CN}$ was added and the resulting solution incubated at room temperature (RT) overnight. $\mathrm{NaBH}_{3} \mathrm{CN}$ and acetaldehyde negatively impact enzyme activity (unpublished data), resulting in low hydrolysis rates. For this reason, three different protocols of $\mathrm{NaBH}_{3} \mathrm{CN}$ and acetaldehyde removal were evaluated and the one resulting in the best hydrolysis yield was selected (Supplementary Information, SI). Treated DNA was precipitated and desalted via addition of cold IPA, washed with 70\% IPA and 100\% IPA sequentially, dried under a stream of $\mathrm{N}_{2}$, and stored at $-20{ }^{\circ} \mathrm{C}$ until analysis. The DNA recovery $(\sim 98 \%)$ for each sample was assessed by UV-Vis-spectrophotometry.

To evaluate concentration-dependent formation of DNA adducts due to acetaldehyde exposure, CT-DNA ( $1 \mathrm{mg})$ was incubated with increasing amounts of acetaldehyde $(0$, $1,2.5,5,25$, and $50 \mathrm{mmol}$ ) and processed as above. Acetaldehyde concentrations were selected to follow experimental procedures previously reported $[8,13]$.

\subsection{DNA Hydrolysis and Quantification}

DNA was solubilized in $1 \mathrm{~mL}$ of $10 \mathrm{mM}$ Tris- $\mathrm{HCl} / 5 \mathrm{mM} \mathrm{MgCl}_{2}$ buffer. DNA concentrations were assessed by UV-Vis-spectrophotometry. A total of $250 \mu \mathrm{g}$ of DNA was hydrolyzed as reported [11]. The digestion yields were assessed by quantifying dG by UPLCUV (Ultimate 3000, Thermo Scientific, Waltham, MA, USA). The recovery of DNA adducts was evaluated by adding a mixture of isotopically labeled internal standards ( $100 \mathrm{fmol}$ of $\left[{ }^{15} \mathrm{~N}_{5}\right] N^{2}$-ethyl-dG, $\left[{ }^{15} \mathrm{~N}_{5}\right] N^{6}$-methyl-dA, and [D $\left.\mathrm{D}_{4}\right] \mathrm{POB}-\mathrm{dT}$ ) into the samples [12].

\subsection{Sample Purification and Enrichment}

Hydrolyzed DNA samples were purified by HPLC fraction collection (FC). The system consisted of an HPLC (Ultimate 3000, Thermo Scientific, Waltham, MA, USA), equipped with a C18 column $(4.6 \times 250 \mathrm{~mm}, 100 \AA$ Á, $5 \mu \mathrm{m}$ Luna-Phenomenex, Torrance, CA, USA). Two different FC methods were developed and optimized. The first method was used during the initial screening experiments: the instrument was operated at $25{ }^{\circ} \mathrm{C}$ with a multistep gradient using $\mathrm{H}_{2} \mathrm{O}$ and $\mathrm{MeOH}$ as mobile phase $\mathrm{A}$ and $\mathrm{B}$, respectively. The eluent was held at $2 \% B$ and $0.5 \mathrm{~mL} / \mathrm{min}$ for $5 \mathrm{~min}$, brought to $1 \mathrm{~mL} / \mathrm{min}$ in $1 \mathrm{~min}$, then to $15 \% \mathrm{~B}$ in $24 \mathrm{~min}$, to $35 \%$ in $5 \mathrm{~min}$, and finally to $100 \% \mathrm{~B}$ in $5 \mathrm{~min}$. This was followed by a wash at $100 \%$ B for $5 \mathrm{~min}$ and re-equilibration. Detection was accomplished using the UV-Vis detector set at $190 \mathrm{~nm}$ and $254 \mathrm{~nm}$. The unmodified nucleobases were collected separately from the other fractions. 
The second method was developed once the standards of the characterized adducts were synthesized to obtain the highest recovery of our analytes. The instrument was operated at $25{ }^{\circ} \mathrm{C}$, performing a multistep gradient at a flow rate of $1 \mathrm{~mL} / \mathrm{min}$ using $\mathrm{H}_{2} \mathrm{O}$ and $\mathrm{MeOH}$ as mobile phase $\mathrm{A}$ and $\mathrm{B}$, respectively. The eluent was held at $2 \% \mathrm{~B}$ for $2 \mathrm{~min}$, brought to $12 \% \mathrm{~B}$ in $10 \mathrm{~min}$, then to $15 \% \mathrm{~B}$ in $3 \mathrm{~min}$, to $20 \% \mathrm{~B}$ in $3 \mathrm{~min}$, and finally to $100 \% \mathrm{~B}$ in $3 \mathrm{~min}$. This was followed by a wash at $100 \% \mathrm{~B}$ for $5 \mathrm{~min}$ and reequilibration. As reported above, detection was accomplished using the UV-Vis detector probing two different wavelengths at 190 and $254 \mathrm{~nm}$. Unmodified nucleobases were collected separately from the other fractions. All collected fractions were subsequently dried under reduced pressure and stored at $-20{ }^{\circ} \mathrm{C}$ until LC-MS analysis.

\subsection{Oral-Cell DNA Collected from Volunteers Exposed to Known Amounts of Alcohol}

Samples were collected as part of a study conducted at the University of Minnesota. The study was approved by the University of Minnesota Human Research Protection Programs Institutional Review Board. Volunteers were enrolled after signing a consent form and evaluation of the eligibility criteria. Medical history and alcohol-drinking history, both in the past 12 months and lifetime, were obtained through questionnaires. Oral rinse samples collected before and $2 \mathrm{~h}$ after alcohol exposure (resulting in a blood alcohol concentration (BAC) of $0.11 \%$ ) were used to isolate DNA for the analysis of acetaldehydederived DNA adducts. Details of the study are reported in the SI.

\subsection{DNA Isolation and Purification from Oral Rinse Samples}

A total of 18 oral-rinse samples collected from healthy volunteers, nine before and nine after $(2 \mathrm{~h})$ consumption of alcohol, were processed. Samples were centrifuged and the supernatant was removed. The pellet was resuspended in $1 \mathrm{~mL}$ of cell lysis solution and treated with proteinase K (24 h, RT), followed by treatment with RNase A ( $2 \mathrm{~h}$ at RT). Proteins were precipitated with $0.3 \mathrm{~mL}$ of protein precipitation solution. The supernatant was poured into an equal volume of ice-cold IPA (100\%) to precipitate the DNA. Samples were then centrifuged. The supernatant was discarded, and the remaining DNA pellet was washed with $75 \%$ and $100 \%$ cold IPA. The liquid washes were discarded, and the residual IPA evaporated under a mild $\mathrm{N}_{2}$ stream. Dried samples were stored at $-20^{\circ} \mathrm{C}$. The extraction yield was assessed by quantifying the DNA using a UV-Vis-spectrophotometer (BioPhotometer, Eppendorf, Hamburg, Germany). DNA hydrolysis and sample purification and enrichment were performed as reported above.

\subsection{LC Conditions for MS Analysis}

Adductomic methods were optimized using an Orbitrap Fusion Tribrid mass spectrometer (Thermo Scientific, Waltham, MA, USA) interfaced to a nanoUPLC (UltiMate 3000 RSLCnano, Thermo Scientific, Waltham, MA, USA) with a NanoFlex ion source (Thermo Scientific, Waltham, MA, USA), operating in positive ionization mode with a voltage of $2.5 \mathrm{kV}$ and an ion tube temperature of $300{ }^{\circ} \mathrm{C}$. The UPLC system was equipped with a $5 \mu \mathrm{L}$ loop and a reverse-phase column home-packed (silica emitter $230 \times 0.075 \mathrm{~mm}$, 15 um orifice, New Objective, Woburn, MA, USA) with C18 stationary phase (5 $4 \mathrm{~m}, 100 \AA$, Luna-Phenomenex, Torrance, CA, USA). The mobile phase consisted of formic acid $(0.05 \%$ $v / v$ in $\mathrm{H}_{2} \mathrm{O}$, phase-A) and $\mathrm{ACN}(100 \% v / v$, phase-B).

For the untargeted screening, the eluent was held at $2 \%$ B for $2 \mathrm{~min}$, brought to $20 \%$ $\mathrm{B}$ in $24 \mathrm{~min}$, then to $60 \% \mathrm{~B}$ in $10 \mathrm{~min}$, to $98 \% \mathrm{~B}$ in $1 \mathrm{~min}$, and then maintained at $98 \%$ for $4 \mathrm{~min}$. This was followed by a wash at $98 \% \mathrm{~B}$ for $4 \mathrm{~min}$ and column re-equilibration. For the targeted analysis, the eluent was held at 2\% B for $6 \mathrm{~min}$, brought to $35 \% \mathrm{~B}$ in $14 \mathrm{~min}$, then to $98 \%$ B in $2 \mathrm{~min}$, and kept at $98 \%$ B for $2 \mathrm{~min}$, followed by column re-equilibration.

\subsection{DDA-CNL/MS $S^{3}$ Gas-Phase Fractionation Method}

Purified DNA extracted from rat liver was available from previous studies and was used as the matrix for our method development. DNA was enzymatically hydrolyzed and 
purified as reported above. A standard mixture of six isotopically labelled DNA adducts

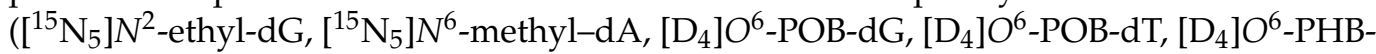
$\mathrm{dG},\left[{ }^{15} \mathrm{~N}_{5}\right] 8-\mathrm{OH}-\mathrm{PdG}$ (structures in SI)) was prepared and spiked in the matrix previously reconstituted in $20 \mu \mathrm{L}$ of LC-MS $\mathrm{H}_{2} \mathrm{O}$ prior to LC-MS analysis.

The MS analysis was performed with Orbitrap detection (resolution of 60,000) in: (i) gas-phase fractionation mode with the mass range of interest split into four scan segments $(m / z$ 197-310, $m / z$ 305-380, $m / z 375-450$, and $m / z$ 445-750) or (ii) in standard mode with a single scan segment $(m / z$ 197-750). In each partial or full scan, quadrupole filtering was used with a maximum injection time of $200 \mathrm{~ms}$ and an automatic gain control (AGC) setting of $5.0 \times 10^{4}$.

For each scan segment, the top five ions were selected for $\mathrm{MS}^{2}$ fragmentation with quadrupole isolation of $1.5 \mathrm{~m} / \mathrm{z}$, using collision induced dissociation (CID) with a normalized collision energy of $30 \%$, maximum injection time of $200 \mathrm{~ms}$, and Orbitrap detection at a resolution of 30,000. An exclusion list of 95 ions (SI) with a mass tolerance of $5 \mathrm{ppm}$ was used, as was dynamic exclusion of $30 \mathrm{~s}$ and an intensity threshold of $2.0 \times 10^{3}$. MS ${ }^{3}$ fragmentation was triggered upon observation of the accurate-mass neutral loss of $2^{\prime}$-deoxyribose (-dR: $116.0474 \pm 0.0006 \mathrm{~m} / z, 5 \mathrm{ppm}$ ) upon $\mathrm{MS}^{2}$ fragmentation. $\mathrm{MS}^{3}$ fragmentation was performed with high-energy collisional dissociation (HCD) with a normalized collision energy of 50\%, maximum injection time of $250 \mathrm{~ms}$, and Orbitrap detection at a resolution of 15,000. This gas-phase fractionation MS method was used for DNA-adduct profiling.

\subsection{Targeted Mass Spectrometry-Based Approach}

To attain the highest level of sensitivity in order to investigate the presence of the adducts, previously characterized in the in vitro experiment, in human oral-cell DNA, a targeted $\mathrm{MS}^{2}$ analysis was performed with the parent ion masses listed in Table 1, and the internal standard ion masses $(m / z 301.1205, m / z 394.1911$, and $m / z$ 424.2191). Subsequently for the absolute quantitation of ethyl-adducts, a targeted $\mathrm{MS}^{2}$ analysis was performed with eight parent ion masses $(m / z$ 256.1292, $m / z$ 261.1605, $m / z$ 280.1404, $m / z$ 285.1718, $m / z$ 296.1353, $m / z$ 301.1205, $m / z$ 394.1911, and $m / z$ 424.2191). The following parameters were set for the analysis: RF lens of $60 \%$, quadrupole isolation window of $1.5 \mathrm{~m} / z$, HCD of $22 \%$, AGC target of $5 \times 10^{4}$, maximum injection time of $50 \mathrm{~ms}$, Orbitrap resolution of 60,000 , and EASY-IC enabled. Frozen DNA samples were thawed and reconstituted in $20 \mu \mathrm{L} \mathrm{H}{ }_{2} \mathrm{O}$ and analyzed.

Table 1. Precursor ion $(m / z), \mathrm{MS}^{2}$ and $\mathrm{MS}^{3}$ spectra base peaks for each putative DNA adduct MS $^{2}$ and $\mathrm{MS}^{3}$ spectra are reported in the Supplementary Information (SI), together with the hypothesized structures) and presence in literature. Data were obtained analyzing DNA incubated with acetaldehyde ( $5 \mathrm{mmol}$ ).

\begin{tabular}{cccc}
\hline Precursor Ion $(m / z)$ & MS $^{2}$ Base Peak $(m / z)$ & MS $^{3}$ Base Peak $(m / z)$ & $\begin{array}{c}\text { Previously Reported } \\
(\mathbf{Y} / \mathbf{N})\end{array}$ \\
\hline 256.1292 & 140.0817 & 95.0240 & $\mathrm{~N}$ \\
\hline 272.1239 & 156.0766 & 95.0604 & $\mathrm{~N}$ \\
\hline 280.1405 & 164.0930 & 136.0618 & $\mathrm{~N}$ \\
\hline 296.1357 & 180.0878 & 135.0300 & $\mathrm{Y}[8]$ \\
\hline 296.1357 & 180.0878 & 145.0508 & $\mathrm{~N}$ \\
\hline 298.1395 & 182.0922 & 112.0506 & $\mathrm{~N}$ \\
\hline 306.1560 & 190.1086 & 136.0616 & $\mathrm{~N}$ \\
\hline 313.1399 & 197.0918 & 127.0502 & $\mathrm{~N}$ \\
\hline 322.1492 & 206.1036 & 162.0773 & $\mathrm{~N}$ \\
\hline 324.1666 & 208.1189 & 148.0616 & $\mathrm{~N}$ \\
\hline 326.1706 & 210.1225 & 138.0661 & $\mathrm{~N}$ \\
\hline
\end{tabular}


Table 1. Cont.

\begin{tabular}{cccc}
\hline Precursor Ion $(m / z)$ & MS $^{2}$ Base Peak $(m / z)$ & MS $^{3}$ Base Peak $(m / z)$ & $\begin{array}{c}\text { Previously Reported } \\
(\mathbf{Y} / \mathrm{N})\end{array}$ \\
\hline 338.1459 & 222.0982 & 135.0300 & $\mathrm{Y}[8]$ \\
\hline 340.1615 & 224.1140 & 135.0300 & $\mathrm{Y}[7]$ \\
\hline 340.1615 & 224.1140 & 136.0506 & $\mathrm{~N}$ \\
\hline 342.1653 & 226.1181 & 112.0504 & $\mathrm{~N}$ \\
\hline 366.1773 & 250.1293 & 180.0880 & $\mathrm{~N}$ \\
\hline 382.1727 & 266.1241 & 178.0722 & $\mathrm{Y}[8]$ \\
\hline 481.2041 & 370.1601 & 112.0505 & $\mathrm{~N}$ \\
\hline 505.2161 & 278.1244 & 112.0505 & $\mathrm{~N}$ \\
\hline 521.2102 & 178.0723 & 112.0505 & $\mathrm{~N}$ \\
\hline 587.2320 & 355.1374 & 204.0878 & $\mathrm{Y}[8]$ \\
\hline 589.2490 & 473.1998 & 195.0989 & $\mathrm{Y}[8]$ \\
\hline
\end{tabular}

\subsection{Method Validation}

The ability of the targeted approach to quantify $N^{2}$-ethyl-dG, $N^{6}$-ethyl-dA, and $N^{4}$ ethyl- $\mathrm{dC}$ was evaluated, and the method was validated. The limits of detection (LOD) for the quantitation of $N^{2}$-ethyl-dG, $N^{6}$-ethyl-dA, and $N^{4}$-ethyl-dC were established using standard solutions of adducts. The limits of quantitation (LOQ), accuracy, and precision of the method were determined by analyzing CT-DNA spiked with different amounts of $N^{2}$-ethyl-dG $(0,2,6,10,40,100 \mathrm{fmol}), N^{6}$-ethyl-dA $(0,0.2,0.6,1,4,10 \mathrm{fmol})$, and $N^{4}$ ethyl-dC $(0,2,6,10,40,100 \mathrm{fmol})$. Each sample was analyzed in triplicate. Background levels of the adducts in CT-DNA were determined by analyzing three nonspiked samples; these amounts were subtracted from the amounts measured in the spiked samples. LODs and LOQs were calculated using the following equations: $\mathrm{LOD}=(3.3 \times \mathrm{sd} / \mathrm{S})$ and $\mathrm{LOD}=(10 \times \mathrm{sd} / \mathrm{S})$, where sd is standard deviation, $\mathrm{S}$ is the slope of the calibration curve, and the multipliers (3.3 and 10) are recommended by International Conference on Harmonization standards [14]. Accuracy was determined by comparing added and measured amounts of the adducts at each level. Precision was determined as intraday coefficients of variation $(\% \mathrm{CV})$ for the triplicate samples. Recovery was determined by adding $\left[{ }^{15} \mathrm{~N}_{5}\right] N^{2}$ ethyl-dG (10 fmol), [ $\left.\mathrm{D}_{5}\right] N^{6}$-ethyl-dA ( $\left.1 \mathrm{fmol}\right)$, and [D ${ }_{5} N^{4}$-ethyl-dC (10 fmol) to CT-DNA, processed as described above and compared to CT-DNA samples with analytes added after processing.

\subsection{Data Processing and Normalization}

Putative DNA adducts were identified from LC-MS ${ }^{3}$ data using Xcalibur 3.0 (Thermo Scientific, Sunnyvale, CA, USA), where only ions which triggered an $\mathrm{MS}^{3}$ event and were unique or increasing in the exposed samples were considered. For relative quantification of a putative DNA adduct in a specific sample, the area of the full-scan extracted ion chromatogram (EIC) with a mass tolerance of $5 \mathrm{ppm}$ was used, and the intensity was further normalized using the following: 1) amount of $\mathrm{dG}$ ( $\mu \mathrm{mol})$ determined in that specific sample and 2) area of the internal standard EIC.

\subsection{Statistical Analysis}

Statistical analyses were performed using SigmaPlot 12.5 (Systat Software, San Jose, CA, USA, https: / / systatsoftware.com/products/sigmaplot/ (accessed on 15 January 2021)). The Student's t-test was used to compare DNA-adduct levels between baseline and $2 \mathrm{~h}$ exposure. Statistical significance was set at $p \leq 0.05$. 


\section{Results}

A top-down DNA adductomic approach was used to comprehensively characterize adducts derived from the interaction of acetaldehyde with DNA. Our DDA-CNL/MS 3 adductomic method can simultaneously screen for multiple DNA adducts by taking advantage of the common structural feature of deoxyribonucleosides: a deoxyribose moiety bound to the nucleobase through a glycosidic bond [15]. This results in a common typical MS fragmentation, which involves the neutral loss of the sugar moiety (116.0474 Da). This common feature is used to program the instrument to trigger further additional $\mathrm{MS}^{3}$ fragmentation of the ions showing the corresponding diagnostic neutral loss and to gain additional information for structural identification. In this work, this powerful comprehensive screening technique was optimized to achieve maximum sensitivity before analysis of the samples.

\subsection{Gas-Phase Fractionation for DNA-Adduct Screening}

Gas-phase fractionation (GPF) in LC-MS analysis is defined as the division of the mass range of interest into multiple segments. The ability of GPF to improve the measurement of trace levels of DNA adducts was tested in a sample matrix by analyzing rat-liver DNA spiked with standards. A mixture of six isotopically labelled DNA adducts (structures in SI) were analyzed using a DDA-CNL/MS 3 method with and without GPF in the full-scan data acquisition. Full-scan data $(m / z 250-750)$ collected from analysis of a similar sample were first used to evaluate the $m / z$ mass distribution used to guide the determination of the GPF $m / z$ precursor windows for testing (Figures S1 and S2). The full-scan range was divided into four $m / z$ ranges with an overlap of $5 \mathrm{Da}(m / z$ 197-310, $m / z 305-380, m / z$ 375-450, and $m / z$ 445-750). Comparison of the method with and without GPF was done by comparing the number of ions undergoing $\mathrm{MS}^{2}$ and $\mathrm{MS}^{3}$ fragmentation, including those for the isotopically labelled standards (Figures S1 and S2).

Across two sample sets, an average of 2083 and 240 ions triggered an $\mathrm{MS}^{2}$ and MS 3 event, respectively, when GPF was used, and 1616 and 210 ions triggered an $\mathrm{MS}^{2}$ and MS ${ }^{3}$ event, respectively, when GPF was not used. A total of five and two standards triggered $M^{2}{ }^{2}$ and $M^{3}$ events when GPF was used. On the other hand, only one standard triggered $\mathrm{MS}^{2}$ and MS ${ }^{3}$ events when GPF was not used. Results demonstrated that GPF can be a useful tool for increasing overall detection coverage of our method; therefore, this technique was used to perform the screening in vitro.

\subsection{Screening of Acetaldehyde-Derived DNA Adducts in Exposed CT-DNA Using LC-HRMS in GPF-DDA-CNL/MS ${ }^{3}$ Scan Mode}

To comprehensively profile acetaldehyde-derived DNA adducts, we investigated the in vitro reactivity of acetaldehyde with DNA. DNA samples were subjected to $\mathrm{NaBH}_{3} \mathrm{CN}$ reduction to stabilize any Schiff bases generated, following a previously described procedure [12]. Purified DNA was exposed to acetaldehyde and re-isolated using our optimized procedure involving DNA precipitation with IPA (SI). DNA was then resuspended in Tris buffer, and after enzymatic hydrolysis and sample enrichment, the samples were analyzed by LC-HRMS.

A rigorous data-analysis workflow was followed to classify those detected ions which are DNA adducts (Figure 1). The use of our untargeted DNA adductomic approach resulted in the detection of $399 \mathrm{MS}^{3}$-triggering ions in the acetaldehyde-exposed sample. Careful scrutiny of the $\mathrm{MS}^{2}$ and $\mathrm{MS}^{3}$ spectra for each $\mathrm{MS}^{3}$-triggering ion confirmed that the fragments observed were consistent with a DNA adduct and used to exclude any $\mathrm{MS}^{3}$-triggering ions resulting from artifacts or false positives. Specifically, for each ion, the $\mathrm{MS}^{3}$ spectrum was scrutinized to i) confirm the presence of one of the nucleobases and/or its fragments as product ions and ii) evaluate that the accurate mass corresponding to the modification accounts for a realistic chemical formula. Furthermore, the peak shape of the precursor extracted ion chromatogram (EIC) was evaluated to confirm its Gaussian-like shape and a minimum of four sticks across the peak. Finally, the retention times of the 
full scan, $\mathrm{MS}^{2}$ and $\mathrm{MS}^{3}$ spectra were evaluated to confirm that they coincided. Full-scan EICs for all candidate DNA-adduct ions were generated for the exposed and nonexposed samples, and only ions that were uniquely present or increasing (with a signal intensity at least three-fold higher) in the exposed sample were further considered.

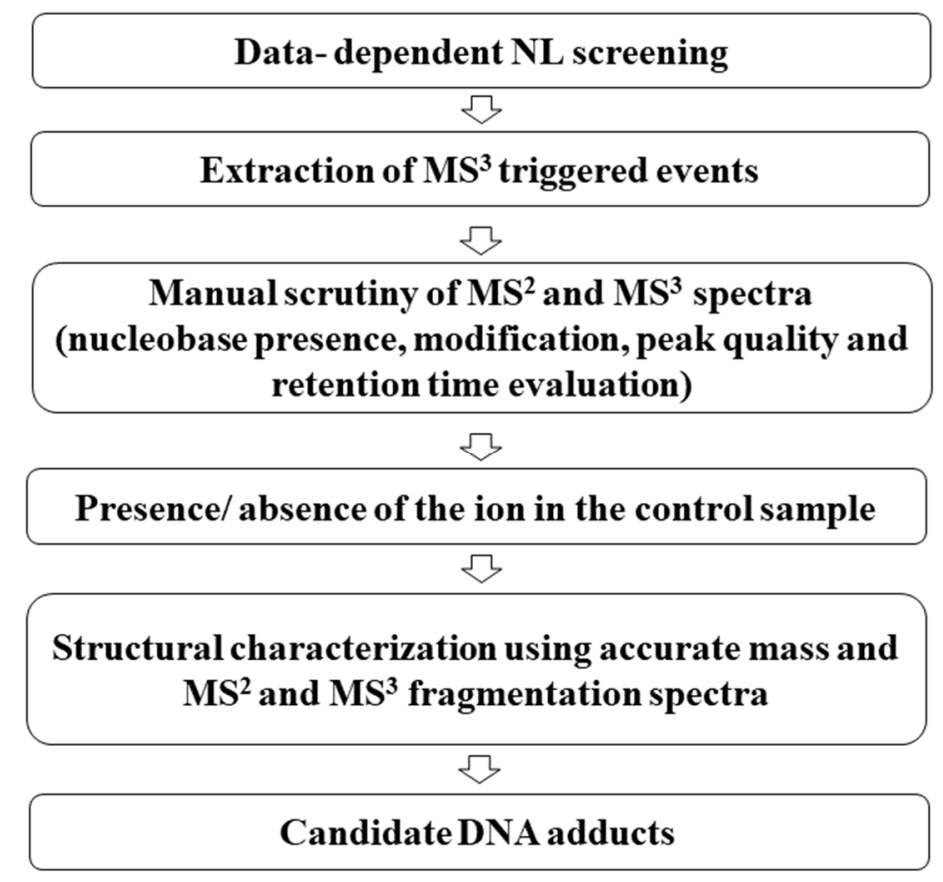

Figure 1. DNA-adductomics data-analysis workflow for DNA-adducts discovery.

This scrutiny of the ions identified by our DNA adductomic approach resulted in the identification of 22 DNA adducts in CT-DNA exposed to acetaldehyde ( $5 \mathrm{mmol}$ ) with $\mathrm{NaBH}_{3} \mathrm{CN}$ reduction. Putative structures were assigned based on $\mathrm{MS}^{2}$ and MS ${ }^{3}$ spectra (SI) and ion masses reported in Table 1. The spectra and structural assignments of the three most abundant DNA adducts, based upon the precursor ion signal intensities in the total ion chromatogram (TIC), were confirmed by comparison with synthetized standards and are shown in Figure 2.

Figure 2 shows the $\mathrm{MS}^{2}$ and $\mathrm{MS}^{3}$ spectra for the three most intense parent ions $(\mathrm{m} / \mathrm{z}$ 256.1292, 280.1404, and 296.1353) detected upon exposure of purified DNA to acetaldehyde. The latter is consistent with the known $N^{2}$-ethyl-dG (Figure 2, panel C) and the fragmentation spectra agree with those previously reported [16-19]. The $m / z 256.1292$ mass is consistent with that of protonated ethylated deoxycytidine. The MS ${ }^{2}$ spectrum (Figure 2, panel A) is dominated by a single ion $(\mathrm{m} / z$ 140.0818) with a mass consistent with the neutral loss of deoxyribose (116.0474 Da). The $\mathrm{MS}^{3}$ spectrum contains an ion which can be assigned to protonated cytosine $(\mathrm{m} / z$ 112.0505) and two ions assignable to cytosine fragment ions $(m / z 95.0240$ and 69.0448) [18]. Similarly, the $m / z 280.1404$ ion is consistent with protonated ethylated deoxyadenosine [18]. Its $\mathrm{MS}^{2}$ spectra is consistent with the neutral loss of the deoxyribose, and the $\mathrm{MS}^{3}$ spectra is consistent with the loss of the ethyl group from the $\mathrm{M}^{+}-116$ fragment and adenine-specific fragment ions $(\mathrm{m} / \mathrm{z}$ $136.0618,119.0353$, and 109.0510.) The scrutiny of these spectra and resulting fragments supported the synthesis of $N^{4}$-ethyl-dC and $N^{6}$-ethyl-dA, which were used to confirm the structure of these two adducts. 

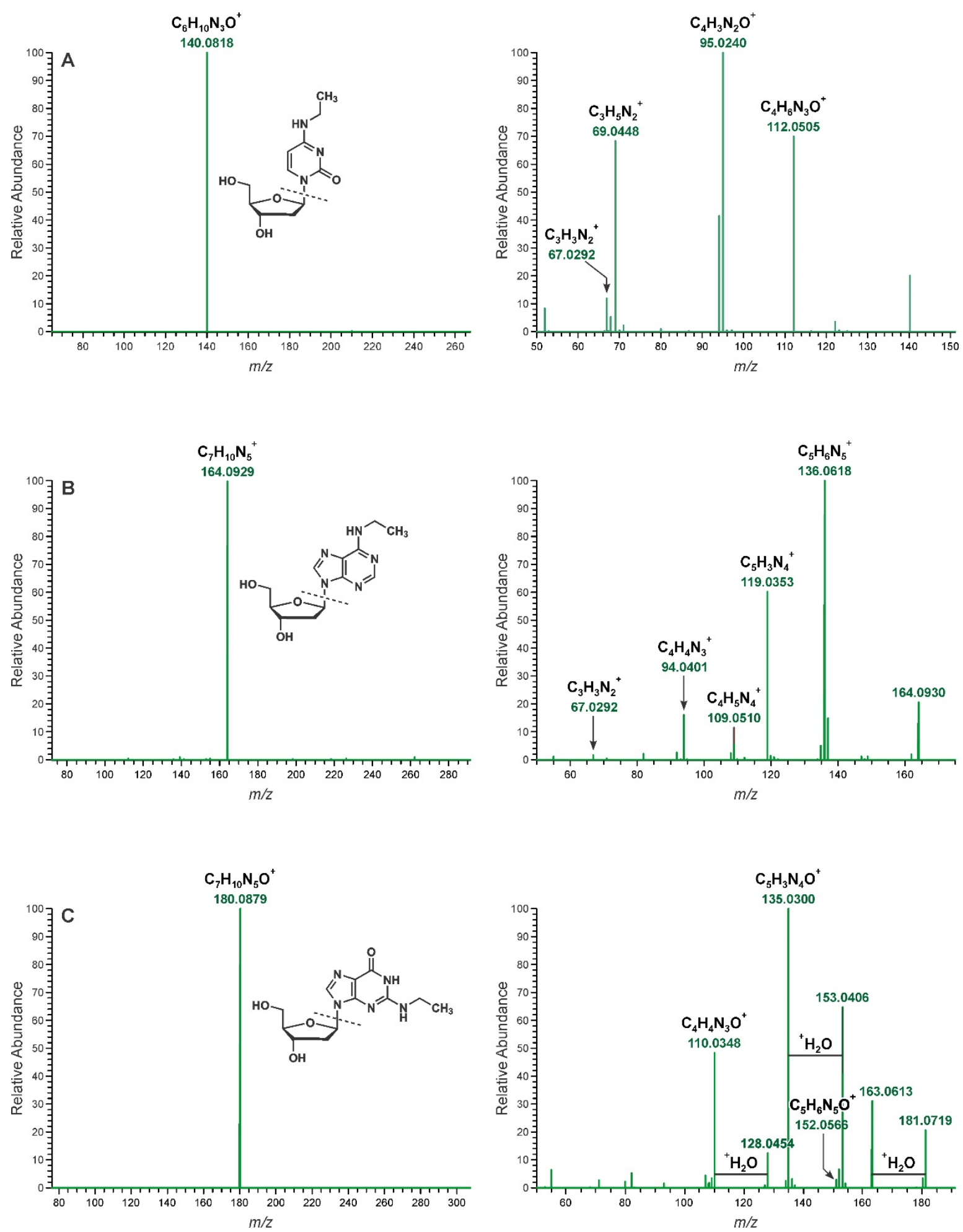

Figure 2. Most intense peaks detected in CT-DNA were assigned to $N^{4}$-ethyl-dC $\left(\mathrm{m} / z\right.$ 256.1292), $N^{6}$-ethyl-dA $(m / z 280.1404)$, and $N^{2}$-ethyl-dG ( $m / z$ 296.1353). Panel (A): $N^{4}$-ethyl-dC MS ${ }^{2}$ and MS $^{3}$ spectra with main fragment structures elucidated. Panel (B): $N^{6}$-ethyl-dA MS ${ }^{2}$ and $\mathrm{MS}^{3}$ spectra with main fragment structures elucidated. Panel (C): $N^{2}$-ethyl-dG MS ${ }^{2}$ and $\mathrm{MS}^{3}$ spectra with main fragment structures elucidated. The three structures were confirmed by comparison with synthetized standards. 


\subsection{DNA-Adduct Characterization and Synthesis of Stable Isotope-Labeled Standards}

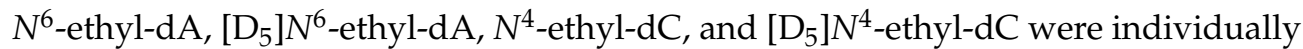
synthesized as reported in Materials and Methods [20-23]. Solid-phase extraction (SPE) purification was not successful and therefore purification was performed using RP-HPLCUV $(254 \mathrm{~nm})$. The adducts were characterized via HRMS infusion, proton and carbon NMR, COSY, and HMQC analysis (Table S1). The amounts of the synthesized compounds were determined by qNMR [24]. The synthesized standards were used to confirm the identity of the analytes detected in our in vitro experiment. A standard solution of the isotopically labelled compounds ([D $\left.\mathrm{D}_{5}\right] N^{4}$-ethyl-dC, $\left[\mathrm{D}_{5}\right] N^{6}$-ethyl-dA, and $\left[{ }^{15} \mathrm{~N}_{5}\right] N^{2}$-ethyl-dG) was coinjected with the previously analyzed CT-DNA sample. The analysis was conducted with a high-resolution targeted approach, monitoring the common loss of $2^{\prime}$-deoxyribose. The retention times of the isotopically labelled standards were consistent with those of the analytes formed by incubation of acetaldehyde and DNA (Figure 3). No chromatographic shoulders or satellite peaks were observed. In addition to co-elution, high-resolution accurate mass and fragmentation of the standards and sample analytes further confirmed the identity of the DNA adducts in the sample (Figure 3).
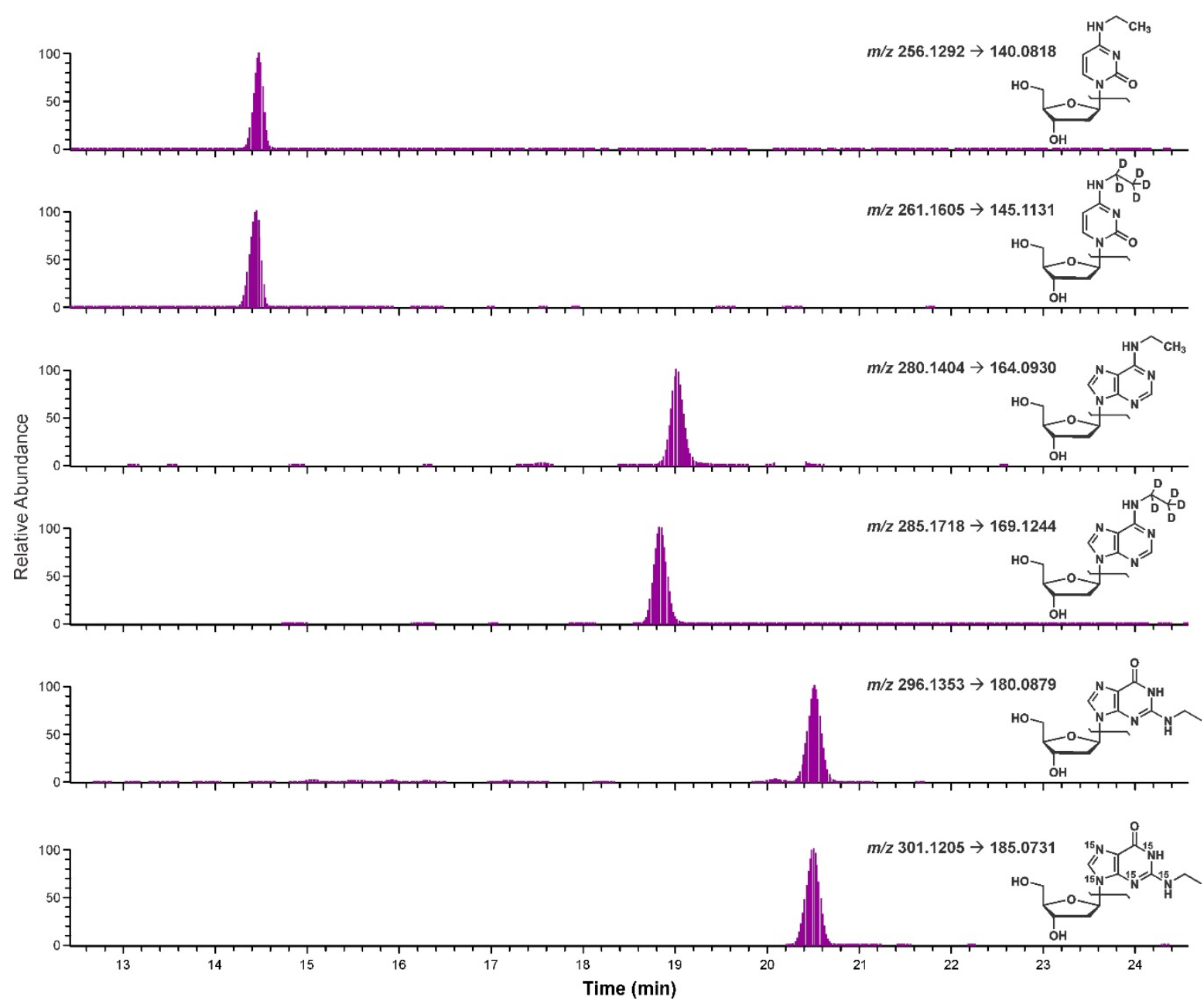

Figure 3. Chromatograms resulting from co-injection of standards with the CT-DNA sample exposed to $5 \mathrm{mmol}$ acetaldehyde. From the top, $N^{4}$-ethyl-dC ( $m / z$ 256.1292), [ $\left.\mathrm{D}_{5}\right] N^{4}$-ethyl-dC $\left(\mathrm{m} / z\right.$ 261.1605), $N^{6}$-ethyl-dA $(m / z 280.1404)$, $\left[\mathrm{D}_{5}\right] N^{6}$-ethyl-dA $(m / z 285.1718), N^{2}$-ethyl-dG $(m / z 296.1353)$, and $\left[{ }^{15} \mathrm{~N}_{5}\right] N^{2}$-ethyl-dG $(m / z 301.1205)$. 


\subsection{Concentration-Dependent DNA-Adduct Generation}

The relationship between acetaldehyde concentration and the generation of the 22 DNA candidate adducts reported in Table 1 was tested (Figure 4 and Figure S3). This experiment was performed to investigate the contribution of exogenous acetaldehyde to the formation of the detected adducts.

A

\begin{tabular}{|c|c|c|c|c|}
\hline$[\mathrm{M}+\mathrm{H}]^{+}$ & $0 \mathrm{mmol}$ & $1 \mathrm{mmol}$ & $5 \mathrm{mmol}$ & $\mathbf{2 5} \mathrm{mmol}$ \\
\hline 256.1292 & $5 \times 10^{6}$ & $5 \times 10^{7}$ & $5 \times 10^{7}$ & $5 \times 10^{7}$ \\
\hline 272.1239 & 0 & 0 & $5 \times 10^{5}$ & $5 \times 10^{6}$ \\
\hline 280.1404 & $5 \times 10^{7}$ & $5 \times 10^{8}$ & $5 \times 10^{8}$ & $5 \times 10^{9}$ \\
\hline 296.1353 & $5 \times 10^{8}$ & $5 \times 10^{9}$ & $5 \times 10^{10}$ & $5 \times 10^{10}$ \\
\hline 296.1357 & $5 \times 10^{5}$ & $5 \times 10^{5}$ & $5 \times 10^{6}$ & $5 \times 10^{7}$ \\
\hline 298.1395 & 0 & 0 & $5 \times 10^{6}$ & $5 \times 10^{7}$ \\
\hline 306.156 & 0 & $5 \times 10^{5}$ & $5 \times 10^{6}$ & $5 \times 10^{7}$ \\
\hline 313.1399 & 0 & $5 \times 10^{6}$ & $5 \times 10^{6}$ & $5 \times 10^{8}$ \\
\hline 322.1492 & $5 \times 10^{5}$ & $5 \times 10^{6}$ & $5 \times 10^{7}$ & $5 \times 10^{7}$ \\
\hline 324.1666 & $5 \times 10^{6}$ & $5 \times 10^{7}$ & $5 \times 10^{8}$ & $5 \times 10^{9}$ \\
\hline 326.1706 & 0 & 0 & $5 \times 10^{7}$ & $5 \times 10^{8}$ \\
\hline 338.1459 & $5 \times 10^{7}$ & $5 \times 10^{8}$ & $5 \times 10^{8}$ & $5 \times 10^{9}$ \\
\hline 340.1615 & $5 \times 10^{7}$ & $5 \times 10^{8}$ & $5 \times 10^{8}$ & $5 \times 10^{10}$ \\
\hline 340.1615 & 0 & 0 & $5 \times 10^{7}$ & $5 \times 10^{7}$ \\
\hline 342.1653 & 0 & 0 & $5 \times 10^{5}$ & $5 \times 10^{7}$ \\
\hline 366.1773 & $5 \times 10^{6}$ & $5 \times 10^{6}$ & $5 \times 10^{8}$ & $5 \times 10^{9}$ \\
\hline 382.1727 & $5 \times 10^{7}$ & $5 \times 10^{7}$ & $5 \times 10^{8}$ & $5 \times 10^{9}$ \\
\hline 481.2041 & 0 & 0 & $5 \times 10^{5}$ & $5 \times 10^{6}$ \\
\hline 505.2161 & 0 & $5 \times 10^{5}$ & $5 \times 10^{6}$ & $5 \times 10^{8}$ \\
\hline 521.2102 & 0 & $5 \times 10^{7}$ & $5 \times 10^{7}$ & $5 \times 10^{8}$ \\
\hline 587.232 & 0 & 0 & $5 \times 10^{6}$ & $5 \times 10^{7}$ \\
\hline 589.249 & 0 & 0 & $5 \times 10^{5}$ & $5 \times 10^{6}$ \\
\hline
\end{tabular}

$0=$ Not detected

\section{B}

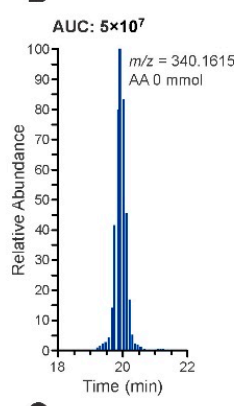

C



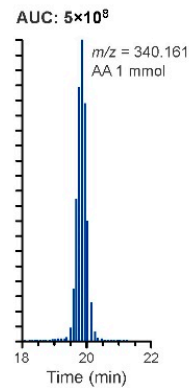

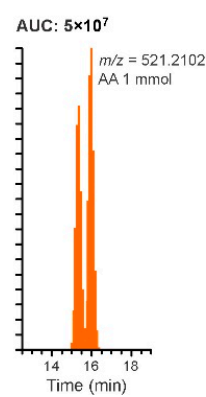

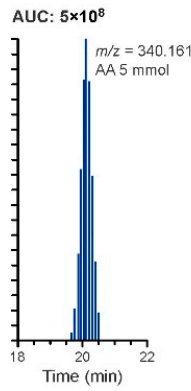
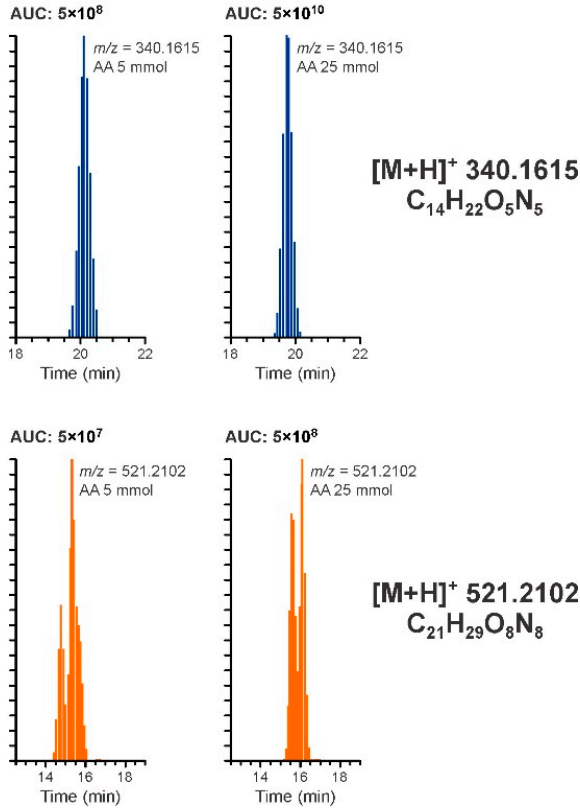



Figure 4. Concentration-dependent formation of the 22 DNA adducts identified in CT-DNA exposed to acetaldehyde. Panel (A): ions detected during the adductomic screening and the average signal intensities at increasing acetaldehyde concentrations $(0,1,5$, and $25 \mathrm{mmol})$. Chromatograms from two representative DNA adducts among those identified are reported illustrating the increase in signal intensity measured as the area under the curve. Panel (B): extracted ion chromatogram of $m / z 340.1615$ at increasing acetaldehyde concentrations. Panel (C): extracted ion chromatogram of $m / z$ 521.2102 at increasing acetaldehyde concentrations.

Adduct levels (intensity of the adduct at a given acetaldehyde concentration) were observed to generally increase with acetaldehyde concentration for all the detected modifications (Figure 4), and some adducts were present in the unexposed DNA. In Figure 4, panels $B$ and $C$, there were two representative examples of DNA-adduct signals increasing with increasing acetaldehyde exposure. Suggested structures of the two ions are reported in the SI. While the ion $m / z 340.1615$ has been hypothesized to be a dG adduct based on its accurate mass and presence of guanine fragmentation in the spectra, for the same reasons, the ion $m / z 521.2102$ has been hypothesized to be a dC-dG crosslink.

In the case of the ethyl-adducts, $\mathrm{N}^{2}$-ethyl-dG showed the most intense instrumental response reaching a signal plateau at high acetaldehyde concentrations (Figure S3). $\mathrm{N}^{4}$ ethyl- $\mathrm{dC}$ gave the least intense instrumental response (Figure S3). For all three adducts, a baseline level was observed in calf thymus DNA.

\subsection{Screening of Acetaldehyde DNA Adducts in Human Oral Cells}

Oral-rinse samples were obtained from nine healthy volunteers before and $2 \mathrm{~h}$ after exposure to a dose of alcohol, calculated on the weight and sex of each individual [25], resulting in a blood alcohol level of $0.11 \%$, measured $1 \mathrm{~h}$ after the dose. DNA was isolated from the oral-rinse samples and processed. Extracted DNA from three participants was pooled to reduce subject-specific variability and increase the amount of DNA to be analyzed, resulting in a total of three DNA samples collected before alcohol exposure and three DNA samples collected after the exposure. 
DNA was treated with $\mathrm{NaBH}_{3} \mathrm{CN}$, and isotope-labeled ethyl-adducts were added as internal standards. Enzyme hydrolysis was performed, and sample clean-up and enrichment via HPLC-fraction collection was completed.

For the NanoLC-HRMS ${ }^{2}$ method, 22 ions detected during the in vitro screening were targeted. The AUC of each putative adduct was normalized by the internal standards AUC and the amount of $\mathrm{dG}(\mu \mathrm{mol})$ measured in the sample.

Out of the 22 DNA adducts detected in vitro and monitored in human oral cells, 17 were detected in the oral DNA samples; six were only detected in the oral cells exposed to alcohol; eight significantly increased in the exposed samples compared to the nonexposed ( $p \leq 0.05)$; and three increased, but with a variability resulting in a nonsignificant difference $(p>0.05)$ (Table 2). Finally, five of the adducts were not detected in any of the oral-cell DNA samples (Table 2).

Table 2. For each ion monitored, the average of the AUC was calculated in nonexposed and exposed oral-cell DNA and normalized by the ISs AUC and $\mu$ mol of dG. The adducts that were only present after exposure are labelled as "+", while those present in samples before and after exposure were labelled as “*”, when the levels increased significantly after exposure $(p \leq 0.05)$.

\begin{tabular}{|c|c|c|c|}
\hline$[\mathbf{M}+\mathbf{H}]+$ & $\begin{array}{l}\text { Average Non-Exposed } \\
\text { (AUC/ } \mu \mathrm{mol} \mathrm{dG})\end{array}$ & $\begin{array}{l}\text { Average Exposed } \\
\text { (AUC/ } \mu \text { mol dG) }\end{array}$ & \\
\hline 272.1240 & 30.8 & 2520 & * \\
\hline $\begin{array}{c}256.1292 \\
\left(N^{4} \text {-ethyl-dC) }\right.\end{array}$ & 2.66 & 392 & * \\
\hline $\begin{array}{c}280.1404 \\
\left(N^{6} \text {-ethyl-dA) }\right.\end{array}$ & 0.235 & 5.15 & * \\
\hline $\begin{array}{c}296.1353 \\
\left(N^{2} \text {-ethyl-dG) }\right.\end{array}$ & 43.2 & 6930 & * \\
\hline 296.1353 & 1.15 & 93.5 & * \\
\hline 298.1397 & 2.10 & 129 & \\
\hline 306.1560 & - & - & \\
\hline 313.1394 & - & 2.48 & + \\
\hline 322.1509 & 40.8 & 1410 & * \\
\hline 324.1666 & 0.0001 & 12.3 & \\
\hline 326.1710 & - & - & \\
\hline 338.1458 & - & 183 & + \\
\hline 340.1615 & - & - & \\
\hline 340.1615 & 0.561 & 32.7 & \\
\hline 342.1659 & - & 47.4 & + \\
\hline 366.1771 & 1.39 & 43.5 & * \\
\hline 382.172 & 81.0 & 10,800 & * \\
\hline 481.2041 & - & - & \\
\hline 505.2153 & - & 1.06 & + \\
\hline 521.2102 & - & 1.94 & + \\
\hline 587.2320 & - & - & \\
\hline 589.2477 & - & 0.533 & + \\
\hline
\end{tabular}

3.6. Quantitation of $N^{4}-e t h y l-d C, N^{6}-e t h y l-d A$ and $N^{2}-e t h y l-d G$ in Human Oral Cells

$N^{4}$-ethyl-dC and $N^{6}$-ethyl-dA were characterized and standards were synthesized. Levels of these adducts were quantified together with those of $N^{2}$-ethyl-dG in oral-cell DNA 
samples from alcohol-exposed volunteers. The method for quantitation of the ethyl-adducts was validated for this study. LODs of $0.13,0.017$, and $0.10 \mathrm{fmol}$ on-column for $N^{4}$-ethyl-dC, $\mathrm{N}^{6}$-ethyl-dA, and $\mathrm{N}^{2}$-ethyl-dG, respectively, were achieved. The concentration ranges for the calibration curves and validation experiments were chosen to cover the range of the levels of adducts found in human oral-cell samples. The calibration curves showed good linearity within the low concentration range $\left(R^{2}>0.99\right)$. The assay accuracy was calculated as a percentage of the added amount of adducts to $50 \mu \mathrm{g}$ of CT-DNA and the average accuracies were 122,137 , and $128 \%(\mathrm{n}=5)$ for $N^{4}$-ethyl-dC, $N^{6}$-ethyl-dA, and $N^{2}$-ethyl-dG, respectively, and good linearity was observed across the tested concentration ranges (Figure S18). Recoveries averaged 46,41 , and $72 \%$. The estimated LOQ in DNA were $33,1.8$, and $37 \mathrm{fmol} / \mu \mathrm{mol} \mathrm{dG}$, respectively.

Representative examples of extracted ion chromatograms for the ethyl-adducts quantitation using NanoLC-HRMS ${ }^{2}$ are shown in Figure 5 (Panel A). $N^{4}$-ethyl-dC, $N^{6}$-ethyl-dA, and $N^{2}$-ethyl-dG were detected in all samples and the peaks of the analytes co-eluted with their corresponding internal standards. The amounts of these ethyl-adducts in oral-cell DNA before and after alcohol exposure are shown in Figure 5 (Panels B-D). The average levels of $N^{4}$-ethyl-dC, $N^{6}$-ethyl-dA, and $N^{2}$-ethyl-dG in samples after exposure were 12 , 0.16 , and $208 \mathrm{pmol} / \mu \mathrm{mol} \mathrm{dG}$, respectively, whereas in samples before exposure they were $0.08,0.007$, and $1.30 \mathrm{pmol} / \mu \mathrm{mol} \mathrm{dG}$, respectively. The levels of the three adducts all showed a significant increase in the samples collected after alcohol exposure (Figure 5). A negative control using buffer and a positive control using CT-DNA were included and worked up in the same way together with the other samples to ensure data quality. No contamination was observed in the negative controls.
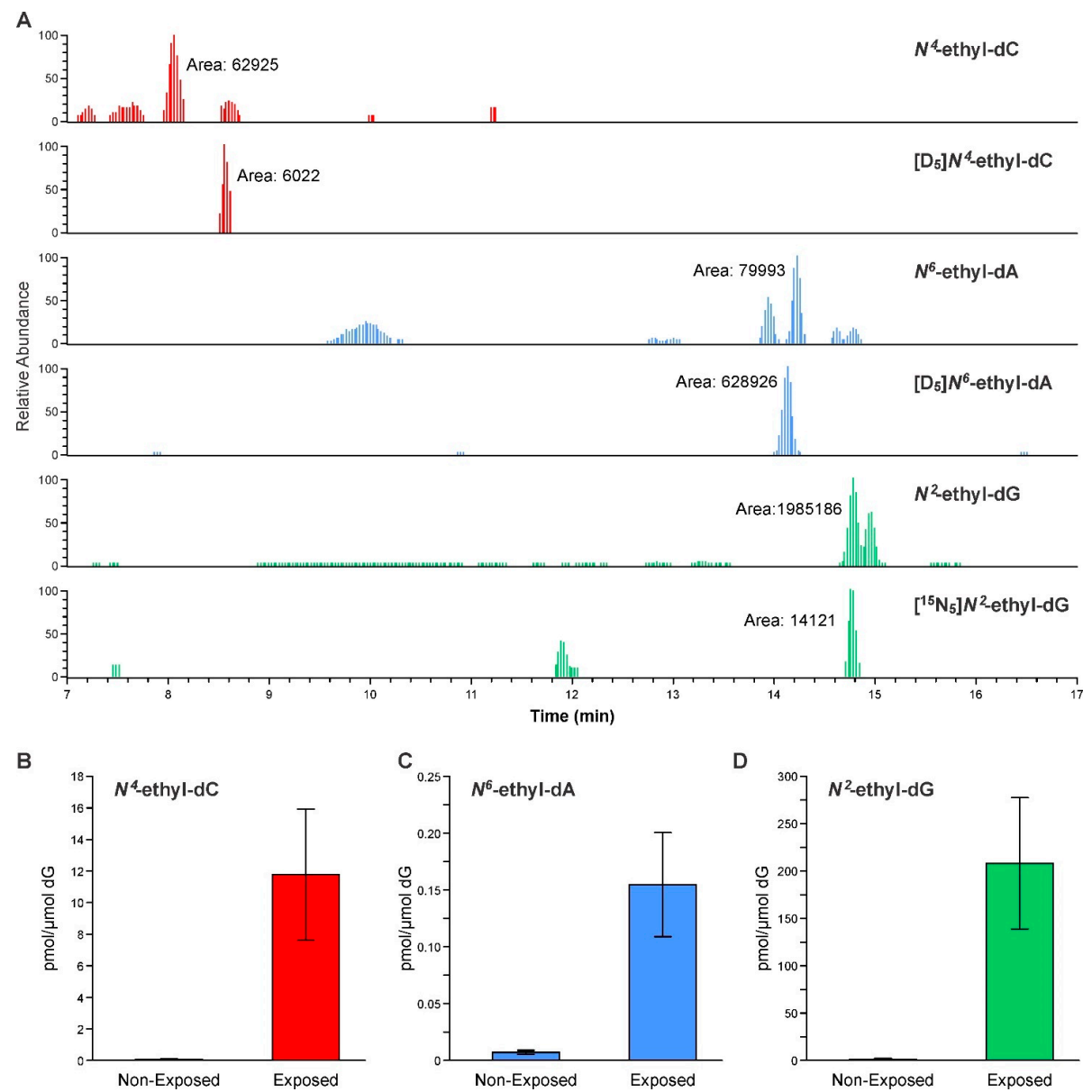

Figure 5. Panel (A): NanoLC-HRMS ${ }^{2}$ chromatograms of ethyl-adducts in human oral-cell DNA isolated from alcoholexposed volunteers. Amounts of $N^{4}$-ethyl-dC (panel (B)) volunteers, $N^{6}$-ethyl-dA (panel (C)) volunteers, and $N^{2}$-ethyl-dG (panel (D)) (pmol/ $\mu \mathrm{mol} \mathrm{dG)} \mathrm{in} \mathrm{human} \mathrm{oral-cell} \mathrm{DNA} \mathrm{of} \mathrm{nonexposed} \mathrm{and} \mathrm{alcohol-exposed} \mathrm{volunteers.}$ 


\section{Discussion}

Our work presents a method for comprehensive analysis of acetaldehyde-derived DNA adducts in oral-cell DNA from volunteers exposed to alcohol. The method was used to screen DNA exposed to acetaldehyde using a high-resolution/accurate-mass data-dependent constant-neutral-loss-MS ${ }^{3}$ (DDA-CNL/MS ${ }^{3}$ ) DNA adductomic approach resulting in the identification of 22 acetaldehyde-derived DNA modifications-some of which have not been described before.

This work was done to expand upon previous studies that characterized reactions of acetaldehyde with DNA and focused on the major covalent binding occurring to dG, while only suggesting the occurrence of reactions with $\mathrm{dC}$ and $\mathrm{dA}[7,8,13]$. These previous studies were done using less-selective, and therefore often less-sensitive, technologies in comparison to the ones used in this study, limiting the ability to perform the simultaneous identification and quantitation of multiple modifications.

The LOD of the DDA-CNL/MS 3 method is limited either by the ion capacity of the Orbitrap to detect ions in the full-scan acquisition or the rate at which $\mathrm{MS}^{2}$ spectra can be acquired. Background ion signal in DNA adductomic analyses is many orders of magnitude higher than the DNA-adduct signals which results in low injection times, and thereby limiting the number of analyte ions entering the Orbitrap for detection [26]. To mitigate this issue, the sensitivity of the standard full-scan DDA-CNL/MS ${ }^{3}$ method was enhanced by the implementation of a procedure called "gas-phase fractionation"(GPF), an approach which has been used in the fields of proteomics, metabolomics, and lipidomics to enhance the detection of low levels of analytes of interest [27-29]. The use of GPF breaks the full-scan range of interest into multiple small ranges resulting in longer injection times by limiting the mass range of ions sampled in a given full-scan detection event. In this study, a comparison of the performance of the standard method with that of a GPF version was done where the full-scan range was divided into four segments, with overlaps of $5 \mathrm{Da}$. The GPF version outperformed the standard method as summarized in Figures S1 and S2, with an average of $2083\left(\mathrm{MS}^{2}\right)$ and $240\left(\mathrm{MS}^{3}\right)$ triggered ions for the GPF method, and $1616\left(\mathrm{MS}^{2}\right)$ and $210\left(\mathrm{MS}^{3}\right)$ triggered ions for the standard method. Five and two spiked-in DNA adducts triggered $\mathrm{MS}^{2}$ and $\mathrm{MS}^{3}$ events, respectively, with the GPF method, compared to one spiked-in DNA adduct for both $\mathrm{MS}^{2}$ and $\mathrm{MS}^{3}$ events when the standard method was used. These results demonstrate that GPF can be a useful tool for increasing overall detection coverage of this method; therefore, this technique was used to perform in vitro screening.

The optimized method was used to comprehensively profile acetaldehyde-DNA adducts in CT-DNA exposed to acetaldehyde and treated with $\mathrm{NaBH}_{3} \mathrm{CN}$ to reduce and stabilize any Schiff bases which formed. Following a rigorous data analysis (Figure 1), 22 DNA adducts were detected and the high-quality spectra and the accurate masses obtained allowed for the assignments of chemical formulas and putative structures, including many $\mathrm{dA}, \mathrm{dC}, \mathrm{dT}$, and $\mathrm{dG}$ adducts (Table 1 and $\mathrm{SI}$ ). Several of the assigned DNA adducts were previously described, including $N^{2}$-ethyl-dG $\left(m / z\right.$ 296.1357) and $1, N^{2}$-propano-dG $(m / z$ 338.1459) which were detected in vivo [6,30-32]. Additionally, Wang and coworkers first demonstrated the generation of $N^{2}$-dimethyldioxane-dG $(\mathrm{m} / z$ 382.1727) and of the crosslink $m / z$ 587.2324 [8]. The crosslink $m / z 589.2420$ has also been reported as reduction product of $m / z$ 587.2324 [9,33-35]. Our DNA adductomic screening analysis identified new DNA adducts including crosslinks involving $\mathrm{dC}$ and monoadducts involving $\mathrm{dA}, \mathrm{dT}$, and $\mathrm{dC}$.

Acetaldehyde is ubiquitous and is a product of physiological processes; therefore, acetaldehyde-derived DNA adducts can be detected in samples not exposed to exogenous sources of this genotoxic compound. To characterize the role that exogenous acetaldehyde has on the formation of the 22 observed DNA adducts, the DNA-adduct ion signals were measured in CT-DNA exposed to increasing amounts of acetaldehyde $(0,1,2.5,5,25$, and $50 \mathrm{mmol}$ ). All adducts showed higher ion intensities as the dose of acetaldehyde augmented. 
The 22 adducts were included in a more sensitive, targeted method for the investigation of acetaldehyde-derived DNA damage in human samples. Among the DNA adducts detected, those resulting from the reduction of Schiff bases formed upon reaction of acetaldehyde with the $N^{2}$ position of $\mathrm{dG}, N^{6}$ position of $\mathrm{dA}$, and $N^{4}$ of $\mathrm{dC}$ corresponded to the most intense signals. The $N^{2}$-ethyl-dG-attributed ion signal was the highest followed by those of the adducts of $\mathrm{dA}$ and $\mathrm{dC}$, in accordance with the observations by Vaca et al., which reported a reactivity order of $d G>d A>d C$ [7]. The identities of these adducts were confirmed by comparison with synthetic standards. The $N^{2}$-ethyl-dG synthetic standard was readily available [6], while $N^{6}$-ethyl-dA and $N^{4}$-ethyl-dC were synthesized. Isotopically labelled versions of the compounds were synthetized as well for quantitation using an isotope dilution method. Accuracy, precision, and limit of detection were determined for this newly developed quantitative method for $N^{2}$-ethyl-dG, $N^{6}$-ethyl-dA, and $N^{4}$-ethyl-dC, which was combined with the targeted detection of the other 19 adducts identified in the initial screening.

The method was tested to investigate alcohol-derived DNA adducts in oral-cell DNA isolated from oral rinses collected from healthy volunteers before and after consumption of an alcohol dose resulting in a $0.11 \%$ BAC. The increase in acetaldehyde concentration in saliva of the study participants after consumption of the alcohol dose was measured by LC-MS. Results from this analysis have been reported in a previous manuscript focusing on the method used for this analysis [36]. In this study, levels of acetaldehyde in saliva were found to increase four- to seven-fold compared to baseline, in samples collected $1 \mathrm{~h}$ after the dose. This measurement confirmed that the dose administered indeed resulted in an increase in the levels of acetaldehyde in the saliva of our study participants.

The results of our work further confirmed the role of alcohol-derived acetaldehyde in the induction of DNA damage in the oral cavity, demonstrated by the increase in the levels of the three major acetaldehyde-derived DNA adducts $N^{4}$-ethyl-dC, $N^{6}$-ethyl$\mathrm{dA}$, and $N^{2}$-ethyl-dG and by the increase in the signal intensity and presence of the other identified adducts in the samples collected after alcohol exposure. These results confirm and expand upon our earlier studies that found a significant increase in the levels of $N^{2}$-ethyl-dG at exposures from alcohol doses resulting in a BAC of $0.03 \%$ [6]. Additionally, the levels of $N^{2}$-ethyl-dG we measured in samples collected before the alcohol dose $(1.30 \mathrm{pmol} / \mu \mathrm{mol} \mathrm{dG})$ were consistent with previously reported levels from a similar study measuring the same adduct in samples collected from volunteers before alcohol exposure $(1.85 \mathrm{pmol} / \mu \mathrm{mol} \mathrm{dG})[5]$.

This is to our knowledge the first application of a DNA adductomic approach for the comprehensive characterization of acetaldehyde-derived DNA adducts and the first application of a targeted adductomic approach for the investigation of alcohol-related DNA damage in the oral cavity. Previously published studies focused on the detection of alcohol-derived DNA damage using nonspecific methodologies like ${ }^{32} \mathrm{P}$-postlabelling or on the quantitation via LC-MS of $N^{2}$-ethyl-dG and $N^{2}$-propano-dG in peripheral whiteblood-cell DNA of alcoholics [37-39]. Indeed, our previous work on oral-cell DNA from volunteers exposed to increasing amounts of alcohol focused exclusively on the quantitation of $N^{2}$-ethyl-dG [6].

Our method allowed for the detection of two new acetaldehyde-derived DNA adducts in oral-cell DNA. Furthermore, three putative crosslinks were detected in oral cavity cells. Crosslinks are known to be potentially highly mutagenic [9,34]. Recently, a study evaluating acetaldehyde crosslink repair assessed the presence of error-prone mechanisms of repair of these adducts, involving the Fanconi Anemia pathways and fork-convergence mechanisms [34]. There is a need for further investigations on the relationship between acetaldehyde-DNA modifications and mutations in humans, especially in susceptible populations, and these studies will benefit dramatically from more comprehensive methods like the one we have developed.

In our work, DNA was treated with $\mathrm{NaBH}_{3} \mathrm{CN}$ to stabilize the Schiff bases. The use of a reducing agent effectively stabilized the imines formed on $\mathrm{dG}, \mathrm{dA}$, and $\mathrm{dC}$; however, the 
treatment may prevent or reduce the chances of detecting other DNA adducts, limiting the ability for this method to truly identify all DNA adducts generated by the reaction with acetaldehyde $[33,34]$. This may require a parallel screening of samples processed without the reducing agent. Therefore, the analysis of samples not treated with $\mathrm{NaBH}_{3} \mathrm{CN}$ is currently ongoing.

Another potential limitation of the work presented is the unknown contribution of bacterial cells in the oral-rinse samples collected. Future investigations should involve a quantitative analysis of bacterial DNA contaminating the samples and evaluation of the use of antibacterial rinses before sample collection. Finally, only three adducts identified in our screening experiment were fully characterized by comparison with internal standards. Further studies will allow the full characterization of the other DNA modifications included in our targeted method, with priority given to crosslink DNA adducts detected in the oral DNA samples.

\section{Conclusions}

In conclusion, our improved DNA adductomic approach allowed the profiling of acetaldehyde-derived DNA adducts in vitro and the creation of a targeted method for the quantitation of the three major acetaldehyde-derived DNA adducts and screening of the 19 other putative DNA adducts. We report for the first time the detection of multiple DNA adducts in volunteers exposed to a specific alcohol dose and the characterization and quantitation of two new acetaldehyde-derived DNA adducts, $N^{4}$-ethyl-dC, and $N^{6}$-ethyl-dA.

Supplementary Materials: The following are available online at https://www.mdpi.com/2218-2 73X/11/3/366/s1. Figure S1: Structures of isotopically labelled standards used for method testing: $\left[{ }^{15} \mathrm{~N}_{5}\right] N^{2}$-ethyl -dG, 2: $\left[{ }^{15} \mathrm{~N}_{5}\right] N^{6}$-methyl-dA, 3: $\left[{ }^{15} \mathrm{~N}_{5}\right] 8-\mathrm{OH}-\mathrm{PdG}, 4:\left[\mathrm{D}_{4}\right] \mathrm{O}^{6}$-POB-dT, 5: [D $4 \mathrm{O}^{6}$-POB$\mathrm{dG}$, and 6: $\left.\left[\mathrm{D}_{4}\right] \mathrm{O}^{6}-\mathrm{PHB}-\mathrm{dG}\right)$. Figure S2. Sample mass spectrum acquired with a DDA-CNL/MS 3 and mass ranges (red lines) chosen for four $m / z$ windows GPF test (197-310, 305-380, 375-450, and 445-750). Figure S3. Concentration-dependent formation of adducts (from the left to the right $N^{4}$-ethyl-dC, $N^{6}$-ethyl-dA, and $N^{2}$-ethyl-dG) in the reaction of acetaldehyde with CT-DNA. Data are based on area of each adduct peak as determined by DDA-CNL/MS ${ }^{3}$. Figure $54 .{ }^{1} \mathrm{H}$ (top) and ${ }^{13} \mathrm{C}$ (bottom) NMR spectra of $N^{6}$-ethyl-dA. Figure S5. ${ }^{1} \mathrm{H}$ (top) and ${ }^{13} \mathrm{C}$ (bottom) NMR spectra of $\left[\mathrm{D}_{5}\right] N^{6}$-ethyl-dA. Figure S6. ${ }^{1} \mathrm{H}$ (top) and ${ }^{13} \mathrm{C}$ (bottom) NMR spectra of $N^{4}$-ethyl-dC. Figure S7. ${ }^{1} \mathrm{H}$ (top) and ${ }^{13} \mathrm{C}$ (bottom) NMR spectra of $\left[\mathrm{D}_{5}\right] N^{4}$-ethyl-dC. Figure S8. COSY (top) and HSQC (bottom) NMR spectra of $N^{6}$-ethyl-dA. Figure S9. COSY (top) and HSQC (bottom) NMR spectra of $\left[D_{5}\right] N^{6}$-ethyl-dA. Figure S10. COSY (top) and HSQC (bottom) NMR spectra of $N^{4}$-ethyl-dC. Figure S11. COSY (top) and HSQC (bottom) NMR spectra of [D $] N^{4}$-ethyl-dC. Table S1. $N^{4}$-ethyl-dC, $\mathrm{D}_{5}-N^{4}$-ethyl-dC, $N^{6}$-ethyl-dA, and $\mathrm{D}_{5}-N^{6}$-ethyl-dA proton and carbon NMR signals in $\mathrm{D}_{5}$-DMSO. Table S2. 3', 5'-bis-O-acetyl-2'-deoxyuridine, 4-chloro-1-N-(3', 5'-bis-O-acetyl-2'-deoxyribosyl)-2pyrimidinoneproton and carbon NMR signals in $\mathrm{CDCl}_{3}$. Figure $\mathrm{S} 12$. $\mathrm{MS}^{2}$ spectra of $N^{4}$-ethyl-dC $(256.1292 \mathrm{~m} / z)$. Figure S13. MS ${ }^{2}$ spectra of [D $\mathrm{D}_{5} \mathrm{~N}^{4}$-ethyl-dC $(261.1605 \mathrm{~m} / z)$. Figure S14. $\mathrm{MS}^{2}$ spectra of $N^{6}$-ethyl-dA $(280.1404 \mathrm{~m} / z)$. Figure $S 15 . \mathrm{MS}^{2}$ spectra of [D $\left.\mathrm{D}_{5}\right] \mathrm{N}^{6}$-ethyl-dA $(285.1718 \mathrm{~m} / \mathrm{z})$. Figure S16. MS ${ }^{2}$ spectra of $N^{2}$-ethyl-dG $(296.1353 \mathrm{~m} / z)$. Figure $S 17 . \mathrm{MS}^{2}$ spectra of $\left[{ }^{15} \mathrm{~N}_{5}\right] \mathrm{N}^{2}$-ethyl-dG $(301.1205 \mathrm{~m} / \mathrm{z})$. Figure S18. Relationship between added amount and measure amount in CT-DNA of A: $N^{2}$-ethyl-dG, B: $N^{6}$-ethyl-dA, and C: $N^{4}$-ethyl-dC. Table S3. Peak area of ethyl-adducts in alcohol-exposed and nonexposed oral cells. Table S4. Average (fmol/ $\mu \mathrm{mol} \mathrm{dG})$, standard deviation (STD), and $p$-value of ethyl-adducts in alcohol-exposed and nonexposed oral cells.

Author Contributions: V.G., S.B. and A.C. conceived the idea of this manuscript and designed the experiments. E.S.C. performed the synthesis and NMR characterization of $N^{4}$-ethyl-dC and $N^{6}$-ethyl-dA and isotopically labelled standards. L.A.M. conducted the alcohol clinical trial, collected samples from participants, and isolated DNA from oral cells. V.G. performed standard purification, DNA sample preparation, high-resolution mass spectrometry, and data analysis. A.C. contributed to the experiments in vitro. P.W.V. contributed to the optimization of LC-MS-based methods in addition to useful inputs on the project. S.B. and S.S.H. supervised the project. All authors have read and agreed to the published version of the manuscript. 
Funding: This research was supported by NIOSH-funded MCOHS ERC Pilot Research Training Program (OH008434) and by the National Cancer Institute funded Grant P01 CA-138338. Mass spectrometry was carried out in the Analytical Biochemistry Shared Resource of the Masonic Cancer Center, supported in part by the U.S. National Institutes of Health and National Cancer Institute (Cancer Center Support Grant CA-77598).

Institutional Review Board Statement: The study was conducted according to the guidelines of the Declaration of Helsinki and approved by the Institutional Review Board (or Ethics Committee) of University of Minnesota (approval \# 1506M74263, 29 March 2016).

Informed Consent Statement: Informed consent was obtained from all volunteers involved in the human study.

Data Availability Statement: The data presented in this study are available in the article and Supplementary Material.

Acknowledgments: We thank Alessia Stornetta for her help during the manuscript preparation, Foster Jacob for his help with the GPF evaluation, Marco Buscemi for his help in the initial in vitro experiments, Giacomo Rizzo for the TOC drawing, and Matt Luedtke for his help with NMR spectra. We acknowledge Bob Carlson for the graphical support.

Conflicts of Interest: The authors declare no conflict of interest.

\section{References}

1. World Health Organization. Global Status Report on Alcohol and Health. License: CC BY-NC-SA 3.0 IGO. Available online: https:/ /apps.who.int/iris/handle/10665/274603 (accessed on 27 September 2018).

2. Begun, A.L.; Murray, M.M. (Eds.) The Routledge Handbook of Social Work and Addictive Behaviors; Routledge: Abingdon, UK, 2020.

3. IARC. Monographs on the evaluation of carcinogenic risks to humans. In Alcohol Consumption and Ethyl Carbamate; IARC Press: Lyon, France, 2010.

4. Stornetta, A.; Guidolin, V.; Balbo, S. Alcohol-derived acetaldehyde exposure in the oral cavity. Cancers 2018, 10, 20. [CrossRef]

5. Chang, J.S.; Hsiao, J.-R.; Chen, C.-H. ALDH2 polymorphism and alcohol-related cancers in Asians: A public health perspective. J. Biomed. Sci. 2017, 24, 1-10. [CrossRef]

6. Balbo, S.; Meng, L.; Bliss, R.L.; Jensen, J.A.; Hatsukami, D.K.; Hecht, S.S. Kinetics of DNA Adduct Formation in the Oral Cavity after Drinking Alcohol. Cancer Epidemiol. Biomark. Prev. 2012, 21, 601-608. [CrossRef]

7. Vaca, C.E.; Fang, J.-L.; Schweda, E.K. Studies of the reaction of acetaldehyde with deoxynucleosides. Chem. Interact. 1995, 98, 51-67. [CrossRef]

8. Wang, M.; Mcintee, E.J.; Cheng, G.; Shi, Y.; Villalta, P.W.; Hecht, S.S. Identification of DNA Adducts of Acetaldehyde. Chem. Res. Toxicol. 2000, 13, 1149-1157. [CrossRef]

9. Lao, Y.; Hecht, S.S. Synthesis and Properties of an Acetaldehyde-Derived Oligonucleotide Interstrand Cross-Link. Chem. Res. Toxicol. 2005, 18, 711-721. [CrossRef] [PubMed]

10. Chen, L.; Wang, M.; Villalta, P.W.; Luo, X.; Feuer, R.; Jensen, J.; Hatsukami, A.D.K.; Hecht, S.S. Quantitation of an Acetaldehyde Adduct in Human Leukocyte DNA and the Effect of Smoking Cessation. Chem. Res. Toxicol. 2006, 20, 108-113. [CrossRef] [PubMed]

11. Wang, M.; Yu, N.; Chen, L.; Villalta, P.W.; Hochalter, A.J.B.; Hecht, S.S. Identification of an Acetaldehyde Adduct in Human Liver DNA and Quantitation asN2-Ethyldeoxyguanosine. Chem. Res. Toxicol. 2006, 19, 319-324. [CrossRef] [PubMed]

12. Carrà, A.; Guidolin, V.; Dator, R.P.; Upadhyaya, P.; Kassie, F.; Villalta, P.W.; Balbo, S. Targeted High Resolution LC/MS3 Adductomics Method for the Characterization of Endogenous DNA Damage. Front. Chem. 2019, 7, 658. [CrossRef] [PubMed]

13. Cheng, G.; Shi, Y.; Sturla, S.J.; Jalas, J.R.; Mcintee, E.J.; Villalta, P.W.; Wang, M.; Hecht, S.S. Reactions of Formaldehyde Plus Acetaldehyde with Deoxyguanosine and DNA: Formation of Cyclic Deoxyguanosine Adducts and Formaldehyde Cross-Links. Chem. Res. Toxicol. 2003, 16, 145-152. [CrossRef] [PubMed]

14. ICH Harmonised Tripartite Guideline. Guidance on Validation of Analytical Procedures: Text and Methodology; Somatek Inc.: San Diego, CA, USA, 1995; pp. 382-395. Available online: https://somatek.com/wp-content/uploads/2014/06/sk140605h.pdf (accessed on 24 February 2021).

15. Balbo, S.; Turesky, R.J.; Villalta, P.W. DNA Adductomics. Chem. Res. Toxicol. 2014, 27, 356-366. [CrossRef]

16. Gregson, J.M.; McCloskey, J.A. Collision-induced dissociation of protonated guanine. Int. J. Mass Spectrom. Ion. Process. 1997, 165, 475-485. [CrossRef]

17. Strzelecka, D.; Chmielinski, S.; Bednarek, S.; Jemielity, J.; Kowalska, J. Analysis of mononucleotides by tandem mass spec-trometry: Investigation of fragmentation pathways for phosphate- and ribose-modified nucleotide analogues. Sci. Rep. 2017, 7, 8931. [CrossRef] [PubMed]

18. Sadr-Arani, L.; Mignon, P.; Chermette, H.; Abdoul-Carime, H.; Farizon, B.; Farizon, M. Fragmentation mechanisms of cy-tosine, adenine and guanine ionized bases. Phys. Chem. Chem. Phys. 2015, 17, 11813-11826. [CrossRef] [PubMed] 
19. Tuytten, R.; Lemière, F.; Van Dongen, W.; Esmans, E.L.; Witters, E.; Herrebout, W.; Van Der Veken, B.; Dudley, E.; Newton, R.P. Intriguing Mass Spectrometric Behavior of Guanosine Under Low Energy Collision-Induced Dissociation: $\mathrm{H}_{2} \mathrm{O}$ Adduct Formation and Gas-Phase Reactions in the Collision Cell. J. Am. Soc. Mass Spectrom. 2005, 16, 1291-1304. [CrossRef] [PubMed]

20. Saladino, R.; Mincione, E.; Crestini, C.; Mezzetti, M. Transformations of thiopyrimidine and thiopurine nucleosides following oxidation with dimethyldioxirane. Tetrahedron 1996, 52, 6759-6780. [CrossRef]

21. Robins, M.J.; Basom, G.L. Nucleic Acid Related Compounds. 8. Direct Conversion of 2'-Deoxyinosine to 6-Chloropurine 2'-Deoxyriboside and Selected 6-Substituted Deoxynucleosides and Their Evaluation As Substrates of Adenosine Deaminase. Can. J. Chem. 1973, 51, 3161-3169. [CrossRef]

22. El-Kafrawy, S.A.; Zahran, M.A.; Pedersen, E.B.; Shiba, S.A.; Søtofte, I.; Møller, J.; Senning, A.; Yao, X.-K.; Wang, H.-G.; Tuchagues, J.-P.; et al. A Novel Route to N6-Alkylated 2'-Deoxyadenosine Using Benzotriazole as a Synthetic Auxiliary. Acta Chem. Scand. 1999, 53, 280-283. [CrossRef]

23. Shin, D.; Switzer, C. A metallo base-pair incorporating a terpyridyl-like motif: Bipyridyl-pyrimidinone.Ag(i).4-pyridine. Chem. Commun. 2007, 42, 4401-4403. [CrossRef]

24. Pauli, G.F.; Chen, S.-N.; Simmler, C.; Lankin, D.C.; Gödecke, T.; Jaki, B.U.; Friesen, J.B.; McAlpine, J.B.; Napolitano, J.G. Importance of Purity Evaluation and the Potential of Quantitative1H NMR as a Purity Assay. J. Med. Chem. 2014, 57, 9220-9231. [CrossRef]

25. Fisher, H.R.; Simpson, R.I.; Kapur, B.M. Calculation of blood alcohol concentration (BAC) by sex, weight, number of drinks and time. Can. J. Public Health 1987, 78, 300-304.

26. Villalta, P.W.; Balbo, S. The future of DNA adductomics. Int. J. Mol. Sci. 2017, 18, 1870. [CrossRef]

27. Calderón-Santiago, M.; Priego-Capote, F.; de Castro, M.D.L. Enhanced detection and identification in metabolomics by use of lc-ms/ms untargeted analysis in combination with gas-phase fractionation. Anal. Chem. 2014, 86, 7558-7565. [CrossRef]

28. Nazari, M.; Muddiman, D.C. Enhanced Lipidome Coverage in Shotgun Analyses by using Gas-Phase Fractionation. J. Am. Soc. Mass Spectrom. 2016, 27, 1735-1744. [CrossRef]

29. Yi, E.C.; Marelli, M.; Lee, H.; Purvine, S.O.; Aebersold, R.; Aitchison, J.D.; Goodlett, D.R. Approaching complete peroxisome characterization by gas-phase fractionation. Electrophoresis 2002, 23, 3205-3216. [CrossRef]

30. Sanchez, A.B.; Garcia, C.C.M.; Freitas, F.P.; Batista, G.L.; Lopes, F.S.; Carvalho, V.H.; Ronsein, G.E.; Gutz, I.G.R.; Di Mascio, P.; Medeiros, M.H.G. DNA Adduct Formation in the Lungs and Brain of Rats Exposed to Low Concentrations of [13C2]-Acetaldehyde. Chem. Res. Toxicol. 2018, 31, 332-339. [CrossRef] [PubMed]

31. Garcia, C.C.; Batista, G.L.; Freitas, F.P.; Lopes, F.S.; Sanchez, A.B.; Gutz, I.G.; Di Mascio, P.; Medeiros, M.H. Quantification of DNA adducts in lungs, liver and brain of rats exposed to acetaldehyde. Free Radic. Biol. Med. 2014, 75, S41. [CrossRef] [PubMed]

32. Matsuda, T.; Matsumoto, A.; Uchida, M.; Kanaly, R.A.; Misaki, K.; Shibutani, S.; Kawamoto, T.; Kitagawa, K.; Nakayama, K.I.; Tomokuni, K.; et al. Increased formation of hepatic n2-ethylidene-2'-deoxyguanosine DNA adducts in aldehyde dehydro-genase 2-knockout mice treated with ethanol. Carcinogenesis 2007, 28, 2363-2366. [CrossRef] [PubMed]

33. Sonohara, Y.; Yamamoto, J.; Tohashi, K.; Takatsuka, R.; Matsuda, T.; Iwai, S.; Kuraoka, I. Acetaldehyde forms covalent GG intrastrand crosslinks in DNA. Sci. Rep. 2019, 9, 1-8. [CrossRef] [PubMed]

34. Hodskinson, M.R.; Bolner, A.; Sato, K.; Kamimae-Lanning, A.N.; Rooijers, K.; Witte, M.; Mahesh, M.; Silhan, J.; Petek, M.; Williams, D.M.; et al. Alcohol-derived DNA crosslinks are repaired by two distinct mechanisms. Nature 2020, 579, $603-608$. [CrossRef] [PubMed]

35. Cho, Y.J.; Wang, H.; Kozekov, I.D.; Kurtz, A.J.; Jacob, J.; Voehler, M.; Smith, J.; Harris, T.M.; Lloyd, R.S.; Rizzo, C.J.; et al. Stereospecific formation of interstrand carbinolamine DNA cross-links by crotonaldehyde- and acetaldehyde-derived al-pha-ch3gamma-oh-1,n2-propano-2'-deoxyguanosine adducts in the 5'-cpg-3' sequence. Chem Res. Toxicol. 2006, 19, 195-208. [CrossRef] [PubMed]

36. Dator, R.; Carrà, A.; Maertens, L.; Guidolin, V.; Villalta, P.W.; Balbo, S. A high resolution/accurate mass (hram) data-dependent $\mathrm{MS}^{3}$ neutral loss screening, classification, and relative quantitation methodology for carbonyl compounds in saliva. J. Am. Soc. Mass Spectrom. 2017, 28, 608-618. [CrossRef] [PubMed]

37. Matsuda, T.; Yabushita, H.; Kanaly, R.A.; Shibutani, S.; Yokoyama, A. Increased DNA Damage in ALDH2-Deficient Alcoholics. Chem. Res. Toxicol. 2006, 19, 1374-1378. [CrossRef]

38. Fang, J.L.; Vaca, C.E. Detection of DNA adducts of acetaldehyde in peripheral white blood cells of alcohol abusers. Carcinogenesis 1997, 18, 627-632. [CrossRef] [PubMed]

39. Balbo, S.; Meng, L.; Bliss, R.L.; Jensen, J.A.; Hatsukami, R.K.; Hecht, S.S. Time course of DNA adduct formation in peripheral blood granulocytes and lymphocytes after drinking alcohol. Mutagenesis 2012, 27, 485-490. [CrossRef] 